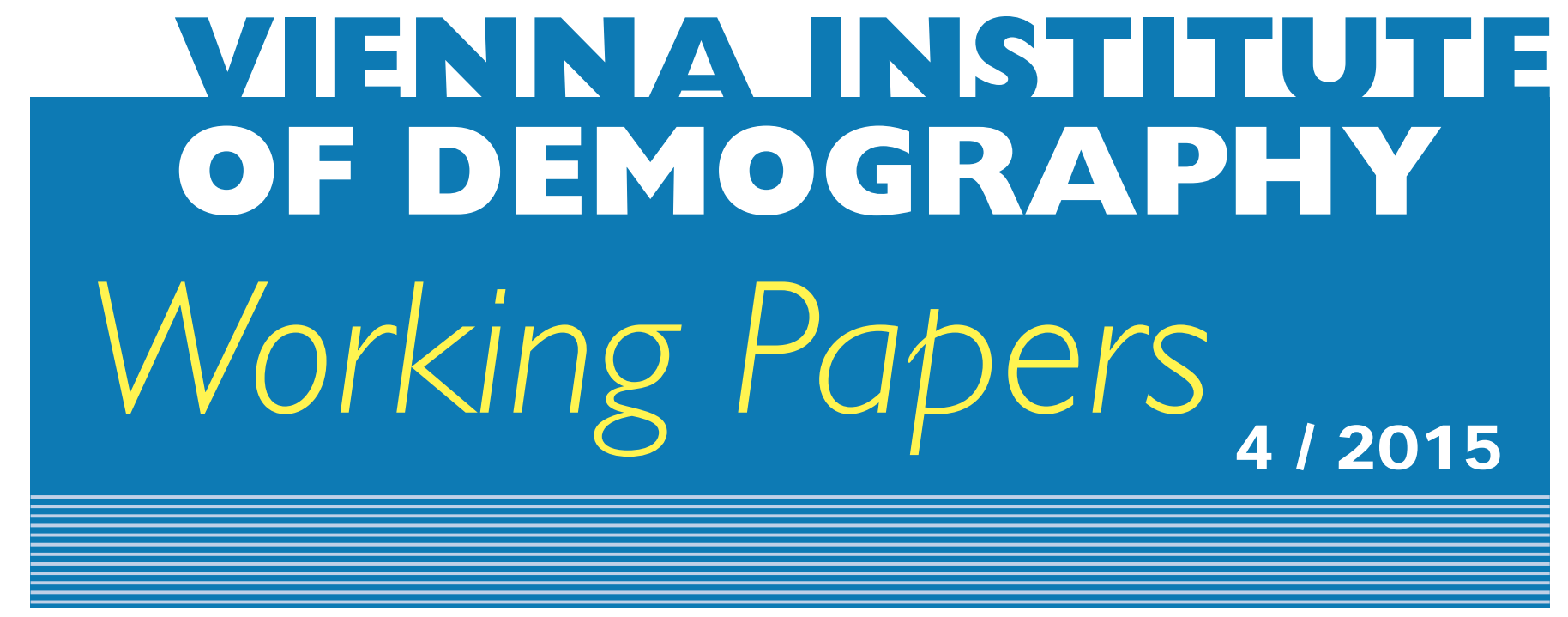

Jeroen Spijker

\title{
Alternative Indicators of Population Ageing: An Inventory
}

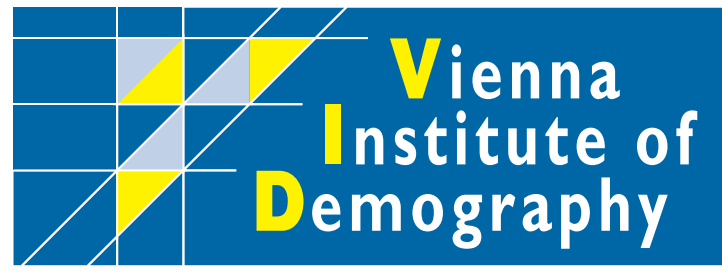

Vienna Institute of Demography Austrian Academy of Sciences

Wohllebengasse 12-14

A-1040 Vienna · Austria

E-Mail:vid@oeaw.ac.at

Website: www.oeaw.ac.at/vid 


\begin{abstract}
The extent, speed and impact of population ageing have often been exaggerated because standard indicators such as the Old-Age Dependency Ratio or Support Ratio do not take proper account of falling mortality, the changing relationship between age and employment, or (usually) both. Neither do such ratios consider the changing composition in terms of educational attainment, human capital or other population characteristics. Not surprisingly, over the last decade or so demographers have developed alternatives. This paper provides an overview of such alternatives and briefly discusses their utility.
\end{abstract}

\title{
Keywords
}

Ageing, dependency ratio, support ratio, alternative indicators of ageing, life expectancy, employment.

\section{Authors}

Jeroen Spijker, "Ramon y Cajal" Research Fellow, Center for Demographic Studies, Barcelona, Spain. Email: jspijker@ced.uab.es.

\section{Acknowledgements}

This research was financed by the Vienna Institute of Demography, where the author spent four months from September to December 2014, and the Spanish Ministry of Economy and Competitiveness under the "Ramón y Cajal" programme (RYC-2013-14851) and "I+D+iRetos" project (CSO2014-60113-R) and conducted in the framework of the European Research Council grant agreement no ERC2013-AdG 323947-Re-Ageing (PI: Sergei Scherbov). The author also would like to thank Miguel Sánchez and Elisenda Rentería for their help with section 2.6. 


\title{
Alternative Indicators of Population Ageing: An Inventory
}

\author{
Jeroen Spijker
}

\section{Background}

Population ageing is the process whereby low fertility and decreasing mortality gives rise to changes in the age structure of the population within which older people form an ever increasing proportion of the total. It is considered to be of economic importance because of a fundamental feature of the economic life-cycle, namely that working-age adults produce more through their labour than they consume, contrary to elderly and children who they directly or indirectly sustain. This economic pattern is only possible because resources flow over time and across generations through a complex system of social, economic, and political institutions (Fürnkranz-Prskawetz et al. 2011). As a population's age structure shifts from having a very young population to one that is dominated by people of working age (initially mainly through the reduction of fertility) this so-called first demographic dividend can be potentially beneficial for its living standards and economic growth. However, as more people survive to old age and older ages within old age, as is the case in all low mortality countries today, for every worker paying income tax and national insurance there are more older citizens who have a higher propensity to be disabled and ill than younger people, leading to greater demands on health and welfare systems. Given that population ageing is only projected to intensify during the coming decades, concern among policy makers has been raised (Burnside 2012; Doyle et al. 2009; Polder et al. 2002; The Select Committee on Public Service and Demographic Change 2013; Wolf \& Amirkhanyan 2010). However, the extent, speed and impact of population ageing have often been exaggerated as standard measures of population ageing such as the Old Age Dependency Ratio (OADR) or its inverse, the Support Ratio (in its simplest form), are based solely on fixed chronological ages. This can be misleading because they implicitly assume that there will be no progress in important factors such as remaining life expectancies, disability rates (Lutz et al. 2008d) or changes in labour force participation (Spijker \& MacInnes 2013b).

\section{Counting the dependent older population}

In an era of increasing life expectancy, especially at higher ages, a number of demographers have been advocating that age should be thought of in terms of years left until death or in proportion to expanding lifespan rather than a fixed chronological age boundary. Defining old age by using life expectancy instead of chronological age was first suggested by Ryder (1975) but over the last decade especially expanded upon by Sanderson and Scherbov (2005, 2007b, a, 2010), Lutz et al. (2008c, d) as well as Baltes and Smith (2003). Measures that adjust for changes in longevity show a much slower pace of population ageing over the last half a century (and in some instances even in the opposite than the expected direction) than those based on the traditional definition of age. 


\section{Counting the working population}

Another point of criticism of the OADR is that it assumes that everyone of working age actually works despite the fact that the knowledge-based service economy keeps young people in education for longer and many older workers voluntarily, or otherwise, retire early (Spijker \& MacInnes 2013b). On top of that, the unemployed also usually depend on the state for their welfare, while homemakers are one of the biggest groups of the non-working population. Conversely, greater sex equality and dual career families have added millions of women workers to the labour market over the past 50 years. These are all reasons why using age to define the working population makes little sense. Indeed, in all high income countries there are more people aged under 65 who are not economically active than people above that age (http://laborsta.ilo.org; own calculations). Given the economic and labour market fluctuations it would thus appear logical to include or correct for the population in paid employement in the denominator of elderly dependency ratios (EDRs) ${ }^{1}$ : any increase in labour force participation (LFP) could potentially reduce per capita costs associated with a growing elderly population while high unemployment would do the opposite. Indeed, a complimentary approach to raising the normal pension age to support ageing populations is to raise the average LFP rate (Scherbov et al. 2014).

\section{Human capital}

As mentioned earlier, the prolongation of education beyond the usual minimum age of 16 is one factor why many young adults are not in employment. However, when higher educated persons do enter the workforce they quickly earn more money than lower educated workers of the same age. Therefore, as more human capital leads to higher productivity (as measured by GDP) this implies that fewer workers are necessary to provide the financial resources needed to care for the 'dependent' elderly. Countries where human capital increases rapidly can therefore be considered an important factor for alleviating the negative effects of population ageing by potentially offsetting declines in the number of people in paid employment. Yet, Philipov et al (2014) argue that higher human capital shaped by earlier schooling, training and work experience also has a downside for government expenditure, namely that human capital utilized during working lives is decisive for the level of income obtained during retirement, i.e. it tends to be higher for individuals who earned more during their working life. The authors therefore came up with an EDRs that takes this into consideration, as will be shown later.

\section{Changing age profiles of income, consumption and wealth}

While standard support and dependency ratios are widely used as indicators for measuring the effects of population ageing on economic development, both use fixed age limits to distinguish between the working and the dependent populations (Prskawetz \& Sambt 2014). Unfortunately, the use of inflexible age categories (even if they are adjusted for changing life

\footnotetext{
${ }^{1}$ In the paper I use Elderly Dependency Ratio as a generic term which may refer to any type of 'old age' dependency ratio, including the conventional OADR.
} 
expectancy) prevents taking into account the changing age profiles of consumption and income across time as a result of demographic shifts. In the past, these changes have been summarised in different types of economic support ratios. For instance, Cuttler (1990) did so by relating a weighted share of the working-age population in the numerator to the weighted sum of all consumers in the denominator. Taking only the retired people in the latter would of course yield an elderly support ratio. By considering the age profiles of consumption and income levels a new set of economic support ratios can be produced, indicators which would, assuming a continuation of the current country-specific social security systems and economic activities, provide better estimates of the consequences of demographic change for the reallocation of resources across ages. For instance, analyses have shown that population ageing can yield a second demographic dividend if younger generations reduce their consumption as a way to increase their wealth and achieve higher consumption in future periods (Prskawetz \& Sambt 2014; Mason \& Lee 2007).

The following, and main, part of the paper provides an overview of studies that propose alternatives to the standard indicator of population ageing - the OADR - by taking into consideration one or more of the aforementioned aspects, i.e. changes in survival, the labour force/productivity, human capital or age-specific income and consumption ${ }^{2}$. The utility or limitations of each are also discussed. Table 5 at the end of the section provides an overview of the discussed ageing indicators and includes, if available, whether short-term projections or forecasts (until about 2020), generally predict an increase or decrease in the indicator ${ }^{3}$.

\section{Towards more Objective Elderly Dependency Ratios}

The level of past, current or future levels in population ageing depend much on how it is measured, but as there is no consensus as to what indicator is best to use it is not clear as to how aged our (or any) society really is. This is in part because the different driving forces behind population ageing in a society, i.e. a decline in fertility, mortality or net migration loss, affect specific ages more than other ages. If, for instance, a population ageing indicator considers the whole population in its calculations, as is the case with the Total Dependency Ratio (TDR), changing fertility levels will have a more immediate effect on the level of population ageing than if the non-adult population is excluded (as in for example the OADR). In case of the latter, there will not be an effect of declining fertility on the ratio until the smaller birth cohorts reach working age, which will then gradually slow down the growth rate of the work force. This is illustrated in Table 1 for Spain, a country that observed one of the

\footnotetext{
${ }^{2}$ As the OADR is a ratio, for comparison purposes the ageing indicators discussed in detail in the paper excludes those that are medians or averages like Sanderson and Scherbov's (2007b) prospective median age (a life-expectancy adjusted median age that shows a much lower increase in median age over the last three decades than the standard median age).

${ }^{3}$ Long-term projections are not provided because they do not exist in the literature for several indicators. Moreover in the case of the indicators developed by the author, too many assumptions would be required e.g. on future age-specific labour force participation rates, making them too speculative.
} 
fastest declines in fertility during the late 1970s and 1980s. As a result, the TDR actually declined faster during the 1980s than the OADR increased. Conversely, the addition of about five million migrants to the Spanish population during the first decade of the $21^{\text {st }}$ century virtually neutralized the ageing of the population, while the abrupt halt of immigration (in fact there has been a net-outmigration of about half a million people, mainly of working age, since 2010) and a stabilized low fertility rate has led to an annual increase of $2.4 \%$ in the OADR and of $1.8 \%$ in the TDR over the 2009-14 period.

Table 1. Annual inter-period \% decline in the Total Fertility Rate (TFR), TDR and OADR, Spain, 1976-2014.

\begin{tabular}{l|rrrrr|rrrr} 
& \multicolumn{5}{|c|}{ Observed } & \multicolumn{4}{c}{ Average annual change (\%) } \\
\hline Indicator & 1979 & 1989 & 1999 & 2009 & 2014 & $1979-89$ & $1989-99$ & $1999-09$ & $2009-14$ \\
\hline TFR & 2.37 & 1.40 & 1.19 & 1.38 & 1.27 & -5.3 & -1.6 & 1.5 & -2.0 \\
\hline OADR & 17.80 & 19.81 & 23.73 & 24.12 & 27.22 & 1.1 & $\mathbf{1 . 8}$ & $\mathbf{0 . 2}$ & $\mathbf{2 . 4}$ \\
TDR & 60.35 & 51.68 & 45.69 & 45.65 & 50.01 & $\mathbf{- 1 . 6}$ & -1.2 & 0.0 & 1.8
\end{tabular}

Source: Calculations based on data from the Spanish National Institute of Statistics (www.ine.es). The ageing indicator that changes (positive or negative) relatively the most between two periods is highlighted in bold.

Secondly, the level of population ageing also depends on how the old-age and working-age populations are defined. Traditionally, fixed age boundaries linked to the statutory pension age and the minimum school-leaving age are used to separate the old-age from the working-age population. With regard to the OADR, the most common of EDRs, which is obtained by dividing the elderly population by the population of working age, the elderly population is usually defined as those aged 65 or older (or sometimes 60+) and the working age population as 15-64, 16-64, 20-64, 20-59 or similar. One important reason population ageing measurements are based on static age boundaries is because of the age of eligibility that is set by public policy for social arrangements related to ageing, particularly public pension plans. The question that can be raised, however, is how useful such a definition really is. Lutz et al. (2008d) even labelled measures of population ageing based solely on fixed chronological ages as 'misleading' because they implicitly assume that there will be no progress in important factors such as remaining life expectancies and disability rates.

\subsection{Years Left vs. Years Lived}

Rather than a fixed age boundary it would be more appropriate to think of age in terms of years left until death or in proportion to the expanding lifespan (Sanderson \& Scherbov 2005). This concept of looking at years of life left rather than years lived is not new. Hersch (1944) introduced the concept of Potential Years of Life (PYL). The idea was quite simple. The "average" person of a given age $x$ still has a potential number of years of life ahead, equalling the average remaining life expectation $\left(e_{x}\right)$ of members of a population. As Panush and Peritz (1996) noted, this measure has some useful applications, including the calculation of the number of potential years in the labour force or retirement. Since then, others have made modifications based on Hersch's idea of potential life years, including Sanderson and Scherbov $(2005,2007 \mathrm{~b}, 2008)$ and Lutz et al. (2008c) who introduced the concept of 
prospective age (initially called standardised age). This is the age of a person in the standard life table who has the same remaining life expectancy as the person of interest ${ }^{4}$. For instance, an Austrian male aged 50 today has the same life expectancy (30 years) as a likewise person aged 41 in 1950 (www.mortality.org). Given their identical life expectancy, one could argue that 41 is the new 50 if 1950 is used as the standard. If applied to a population's median age, one obtains the so called prospective median age or PMA (Lutz et al. 2008c). The same authors also came up with an alternative for the average age of a population, i.e., an 'adjusted' average age that takes age-specific life expectancies into consideration, the Population Average Remaining Years of Life expectancies (PARYL). Here the age-specific remaining life expectancies are weighted by the proportions of the population at each age whose average is then taken to obtain the average remaining years of life of population members. PARYL goes down as population ages.

Another contribution, which anticipated the concept of prospective age, can be found in Ryder (1975, p.16; cited in Sanderson \& Scherbov 2013) who wrote that:

"To the extent that our concern with age is what it signifies about the degree of deterioration and dependence, it would seem sensible to consider the measurement of age not in terms of years elapsed since birth but rather in terms of the number of years remaining until death...

We propose that some arbitrary length of time, such as 10 years, be selected and that we determine at what age the expectation of life is 10 years, that age to be considered the point of entry into old age".

Siegel and Davidson (1984) were the first to apply Ryder's proposal with actual data, while others came (sometimes independently) to similar ideas (see Sanderson \& Scherbov 2013 for an overview). One of such alternative approaches to the conventional way of measuring the proportion of the population considered elderly, usually $60+$ or $65+$, was by Lutz et al. (2008c) who did not make it depend on a fixed age boundary but, rather, on a fixed remaining life expectancy, i.e.:

- Proportion of the population in age groups that have a remaining life expectancy (RLE) of 15 years or less (Prop. RLE15-). Again, the life table is used to derive the age at which RLE equals 15 . As the age at which RLE15- tends to fall between two completed years of age, linear interpolation is applied to obtain the exact age. Subsequently, using population data by single age and sex the total population equal to and above this age is obtained (also through interpolation) and divided by the total population to arrive at the proportion. If longevity increases, the minimum age of people included in Prop. RLE 15increases; "but if the proportion of the total population above the age with an expectancy of 10 [or 15] years falls than this might [also] result from a rapid rise in life expectancy rather than [only due to] the actual ageing of the population" (Siegel \& Davidson 1984; brackets added by author).

\footnotetext{
${ }^{4}$ See the Annex for how prospective age is calculated.
} 
Although PMA and PARYL could be considered indicators of population ageing, they are of little policy value because they concern, respectively, the expected years to live of a middleaged person and of the whole population.

Sanderson and Scherbov (2010) and others (Lutz et al. 2008c; Lutz 2009; Ryder 1975) considered the age at which RLE equals 15 years as the threshold of elderly dependency (with the population equal to or above this threshold considered old age) rather than age 65 because it takes into account falling old-age mortality. If we obtain the population total for the numerator for each sex $s$ separately ${ }^{5}$ as men and women have disparate life expectancies (even at higher ages) Prop. RLE15- is calculated as:

Prop. $R L E 15-=\frac{\sum_{s} \text { population } R L E 15-}{\text { total population }} * 100$

The fact that this age has been rising in most low-mortality countries since half-way last century (a bit earlier for women, a bit later for men) render these elderly 'younger', healthier and fitter than their peers in earlier cohorts.

Likewise, while the OADR defines all people above the statutory pension age as 'dependent', regardless of their economic, social or medical circumstances, it overlooks the fact that many elderly have accumulated substantial assets, may still be working and many have valuable experience or expert knowledge, while others do volunteer work vital to the 'third sector' or look after grandchildren. Sanderson and Scherbov (2007b) thus came up with an alternative to the OADR:

- Prospective Old Age Dependency Ratio (POADR). Here the population with RLE15- ${ }^{6}$ is divided by the population below this age threshold but is at least 20 years old ${ }^{7}$. The age range of the working age population is thus slightly shifted upwards to exclude a large student population most of whom are not (fully) active in the workforce, but include young-old people who could potentially work when the age at old-age threshold is higher than 65 (in most high income countries since around the 1980s):

$P O A D R=\frac{\sum_{s} \text { population RLE15- }}{\text { population } 20+\text { up to age at which } \sum_{s} \text { population RLE15- }} * 100$

When comparing the POADR with the standard OADR we can observe that once the age threshold at which RLE is 15 years or less is above 65 , the ratio becomes higher than the OADR (if we use 20 as the lower boundary of working age in both indicators) as the size of the numerator is reduced and that of the denominator enlarged (Figure 1), but that over the next decades dependency as measured by the POADR is expected to decrease much less in

\footnotetext{
${ }^{5}$ This slight adjustment was first proposed in Spijker \& MacInnes 2013b).

${ }^{6}$ There are also other possible types of prospective old age dependency ratios. For instance, one can take a prospective age, an index year (year of interest) and a standard year and by varying the prospective age and the standard year, one can compute POADRs for different comparative purposes. One example is to assume that remaining life expectancy is kept constant at its observed value for 65 year olds in 2000 as a way to compare with the conventional OADR that divides the $65+$ by the working-age population. The POADR is then the ratio of the number of people at equal to or older than the age threshold (i.e. prospective age 65+) to the number of people between 20 and that prospective age (Sanderson \& Scherbov 2007b).

${ }^{7}$ Rather than 15 or 16 as many older teenagers and young adults still attend secondary or higher education, meaning that most are not yet (fully) active in the workforce.
} 
most countries of the world and in the case of the least developing countries, not at all (Table 2 and Sanderson \& Scherbov 2008).

Figure 1. The OADR, POADR and age at which remaining life expectancy (RLE) equals 15 years. US. 1950-2010.

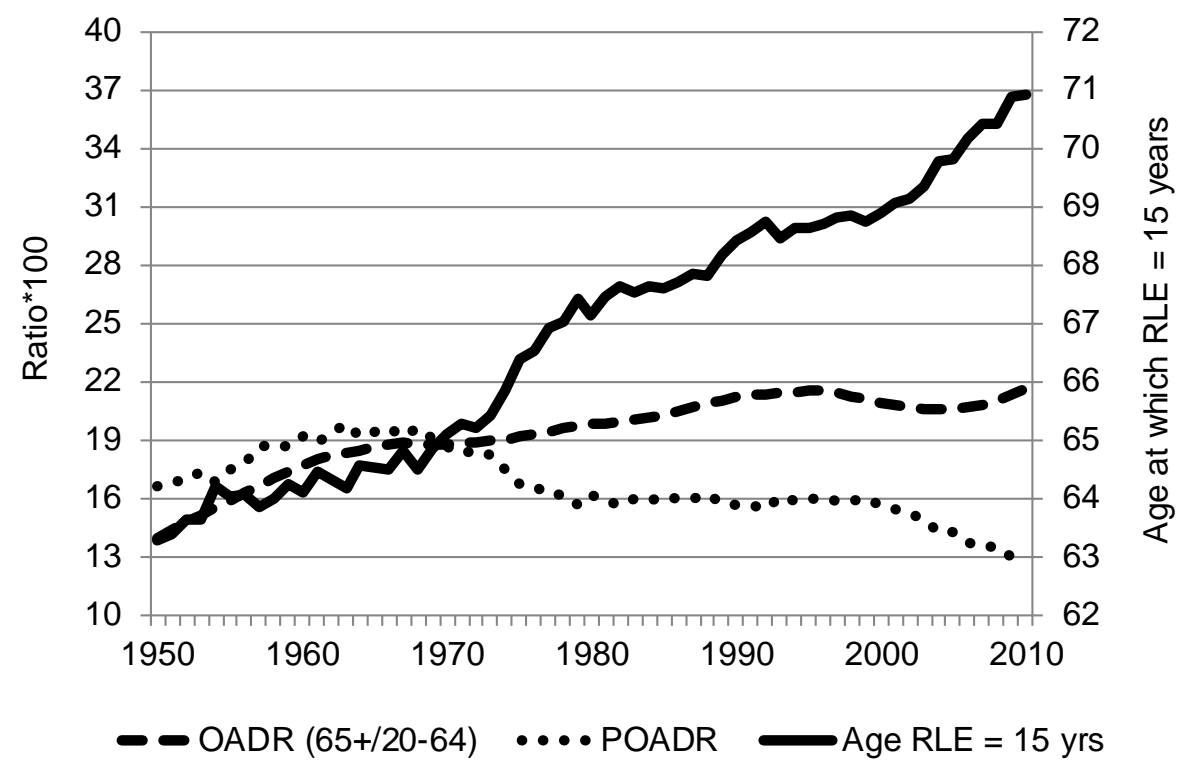

Source: Human Mortality Database (www.mmortality.org)

Table 2. Conventional and prospective measures of population ageing for major world regions, 2005 and 2045

\section{WORLD}

More developed regions Less developed regions ${ }^{\text {a }}$

\begin{tabular}{rr|rr|rr|rr|rr}
\multicolumn{2}{c|}{$\begin{array}{c}\text { Prop. 65+ } \\
\text { (x100) }\end{array}$} & \multicolumn{2}{c|}{ Prop. RLE15- } & \multicolumn{2}{c|}{$\begin{array}{c}\text { Prop. 65+ } \\
\text { x100 }\end{array}$} & \multicolumn{2}{c|}{ Prop. RLE15- } & \multicolumn{2}{c}{ POADR } \\
\hline 2005 & 2045 & 2005 & 2045 & 2005 & 2045 & 2005 & 2045 & 2005 & 2045 \\
\hline $\mathbf{7 . 4}$ & $\mathbf{1 5 . 2}$ & $\mathbf{7 . 4}$ & $\mathbf{1 5 . 2}$ & $\mathbf{6 6 . 3}$ & $\mathbf{6 9 . 8}$ & $\mathbf{6 6 . 3}$ & $\mathbf{6 9 . 8}$ & $\mathbf{1 1 . 9}$ & $\mathbf{1 7 . 7}$ \\
15.3 & 25.3 & 15.3 & 25.3 & 68.7 & 72.8 & 68.7 & 72.8 & 18.2 & 25.7 \\
5.9 & 15.6 & 5.9 & 15.6 & 65.0 & 69.2 & 65.0 & 69.2 & 10.7 & 18.6 \\
3.2 & 5.8 & 3.2 & 5.8 & 61.9 & 65.6 & 61.9 & 65.6 & 10.0 & 10.1
\end{tabular}

${ }^{a}$ Excluding least developed countries

Source: Sanderson \& Scherbov 2008

Even though using RLE15- is an improvement to using a fixed age like 60+ or 65+, the age at which RLE equals 15 years is also arbitrary (e.g. why not 2, 5 or 10 years?). Moreover, the literature tells us that especially health care expenses occur during the last year(s) of life, with little impact from the age at which these deaths occur (Miller 2001; Sanderson \& Scherbov 2010; Seshamani \& Gray 2004; Wong et al. 2011; Zweifel et al. 1999). This perspective of remaining-years has also been applied in the fields of psychology and economics (Bíró 2010; Carstensen 2006; Carstensen et al. 1999; Cocco \& Gomes 2012; Hamermesh 1985; Van Solinge \& Henkens 2010) as such information is essential to good predictions of likely health, social care, pension, housing and other age-related expenditures. 
In Riffe et al (2014), building on Brouard (1986), population age structures were therefore presented in terms of remaining years of life rather than chronological age ${ }^{8}$. This is an even clearer way to show that in times of falling mortality, chronological age becomes an unreliable and insufficient metric of ageing. The reason is because declines in mortality not only change the distribution of age within a population, it also shifts the distribution of remaining lifetimes at each age of that population and attenuates the effect of fertility on population ageing. The authors illustrated this by estimating the remaining lifespans of the 78 million US babyboomers alive in 2011, i.e. at a time when the oldest of this cohort reached the retirement age. Results showed that the dreaded mortality burden of the US boomers is in fact expected to be dampened and stretched over a wider range of years ${ }^{9}$ than were the boomlike onsets of other life transitions experienced earlier by this cohort (e.g. when many of this cohort had children they caused the so-called echo-boom).

While the importance of considering both time already lived as time left to live of the members of a population is propagated in both Sanderson and Scherbov (2007b) and Riffe et al (2014), the former uses remaining life expectancy (RLE) that equates to a population average at a particular age while the latter considers remaining years of life (also labelled as Time-to-Death - TTD) at any age. So while adjusting for changes in life expectancy in determining the old-age threshold -as the indicator RLE15- does-, is better than using a fixed age such as 65 , it could still be criticized for including many elderly who consider themselves healthy. Moreover, it remains a population average measurement as many persons in the corresponding age group may still live another 30 years, while others will die within a few years. Depending on the purpose of the population ageing indicator, using RLE15- may not always be appropriate, such as with regard to elderly health care needs and expenditure given that the literature clearly shows that TTD is a better indicator for health care expenditure than age (Miller 2001). On the other hand, RLE15- does provide a way to define the general elderly population in an era of ever improving old-age survival. Therefore, in Spijker et al (2014) it was proposed to combine time to death (TTD) of up to 5 years with Sanderson and Scherbov's RLE15- ${ }^{10}$ to create an indicator of acute health needs among the elderly population. Using the same denominator as Sanderson and Scherbov we calculate the following:

$P O A D R 5 T T D=\frac{\# \text { men and women in age groups with RLE15- \& TTD }<5}{\text { population } 20+u p \text { to age at which } \sum_{s} \text { population } R L E 15-} * 100$

Results for the US showed that the burden has been stable since 1980 at under three elderly with acute health needs for every adults of working age (according to the Sanderson and Scherbov definition), a rate which is not expected to rise above three until 2028 (Figure 2). Again this suggests that population ageing is not fuelling the demand for health care

\footnotetext{
${ }^{8}$ See both publications for the method employed to decompose and restructure a population by remaining years of life based on information contained in the period life table.

${ }^{9}$ For instance, if we assume that mortality rates starts declining by $2 \%$ per year at each age for this cohort but tapers off to constant mortality by around 2075 according to a logistic pattern, $50 \%$ of boomer deaths will fall between 2032 and 2049 and $10 \%$ will still be alive after 2058 .

${ }^{10}$ Fuchs (1984) had first proposed to combine it with the population aged $65+$.
} 
services but other factors such as progress in medical knowledge and technology, costs of hospitalization and the increasing use of long-term care facilities.

Figure 2. Proportion of the population aged 65+, with a remaining life expectancy of 15 years or less (RLE15-) and with both RLE15- and a time to death (TTD) of less than 5 years, US, 1950-2050.

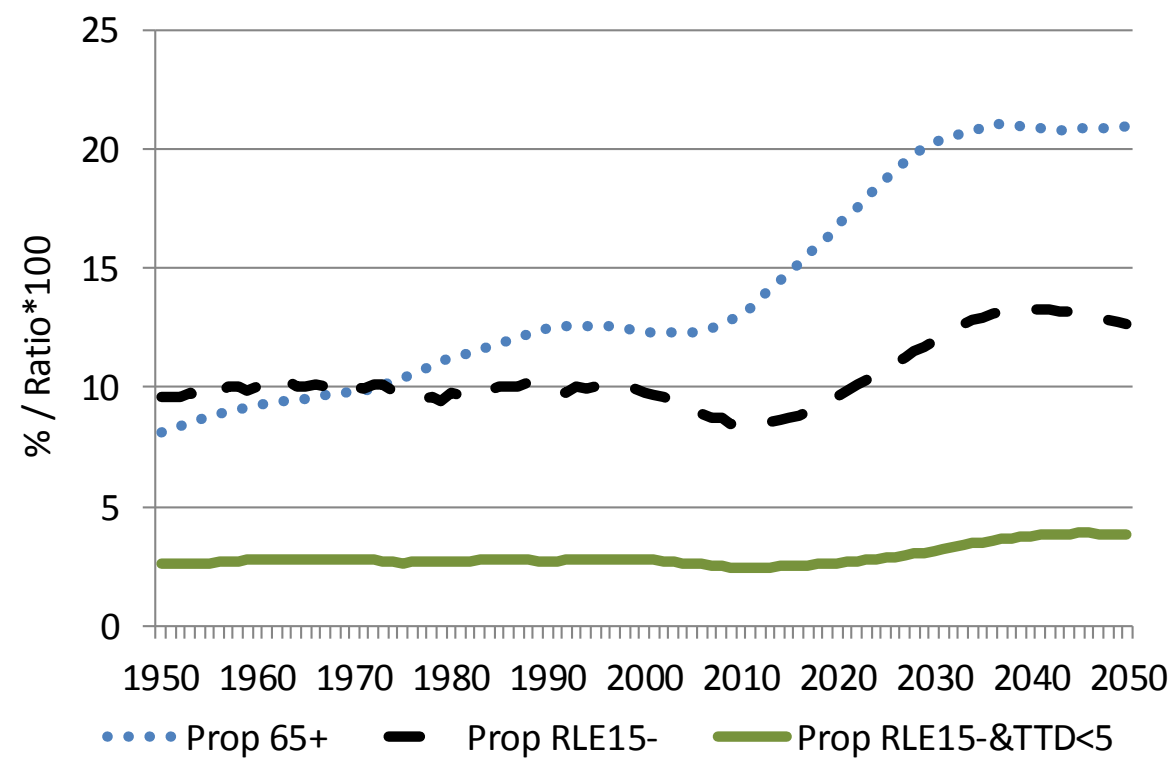

Data source: Sex-specific population and mortality data until 2011 come from the Human Mortality Database (www.mortality.org) and the projected data from the US Census Bureau (www.census.gov).

\subsection{Non-Working to Working Population Ratios}

Key drivers of economic growth include labour supply, productivity, consumption and savings. These tend to vary depending on the position of people in the life cycle (Bloom et al. 2010). Labour supply and productivity and their relationship to population ageing is discussed, while consumption and savings is treated in subsection 2.6.

Changes in population age structure exert a significant influence on economic growth (Bloom et al. 2010). For instance, on the one hand, declining infant and child mortality followed by lower fertility and larger cohorts entering working age results in the first demographic dividend as the labour force grows faster than the (still relatively small) older and younger population who depend on it. Even if nothing else changes, per capita income will increase, but investments in the development of human capital, technological progress, institutions and governance, can boost economic productivity enormously. For instance, it has been suggested that these factors in combination with the demographic dividend were behind the economic miracle of East Asia between 1965 and 1990 (Bloom \& Canning 2008; Bloom et al. 2010). Conversely, one concern regarding the consequences of population ageing is that there will be a rising number of older dependent citizens for every productive worker in employment. However, the size of the employed workforce is driven by many factors other than age as its relationship to the population age structure is rather dynamic, as was detailed 
by Spijker and MacInnes (2013a): The employment rate of women and especially mothers increased dramatically over the last 50 years as systematic gender discrimination was dismantled at school and in the workplace and the 'male breadwinner' employment system weakened. While the ratio of productive workers to dependent citizens was moved upwards by the reduction in the number of young people in the population as fertility declined after the baby boom, it was also driven down by the shortening of careers due to the increase in the labour force level of educational attainment. Moreover, in many western countries less than one half wait until the state retirement age to leave the labour market, either because they can afford to do so or have been made redundant and no longer see any realistic prospect of obtaining employment (ibid. pp. 66-67). On top of that, a substantial proportion of the population of working age does not participate in the workforce, such as students and homemakers, or they do but are unemployed. As the aforementioned factors also fluctuate strongly as a result of economic booms and busts and changes in pension eligibility, the working-age population has become a flawed indicator of the population that is supposed to support the elderly. The same applies to the numerator of the conventional OADR as in highincome countries the number of pensioners exceeds the population aged 65 and older (i.e. the pensioner ratio is greater than one) as public pensions are available at younger ages, either because the statutory retirement age is less than 65 (as e.g. in France and Japan) or it becomes available at a reduced rate at younger ages (Bongaarts 2004). Conversely, in other settings there are fewer people retired than there are people aged 65 or more, especially in settings where there is no or a negligible system of state-financed retirement pensions, forcing many elderly to remain active in the workforce, as is the case in most low-income and even many middle-income countries. For instance, in China there are large rural-urban differences in pension levels and the unemployed and self-employed are still not even covered (Wu 2013), while in Latin America pension coverage was $60 \%$ or less among the $65+$ population in thirteen countries (Rofman \& Oliveri 2012).

For these reason, alternative indicators of the demographic burden of supporting the elderly have been constructed over the last decade or so. For instance, according to Bongaarts (2004) a more accurate indicator of the demographic burden of supporting the elderly ${ }^{11}$ is the ratio of pensioners to workers:

$P W R=\frac{\text { Pensioners }}{\text { Population in paid employment }}$

This ratio is much larger than the conventional OADR in high income countries and particularly in France and Italy ${ }^{12}$.

More akin to the TDR, Vaupel and Loichinger (2006) simply considered the ratio of non-workers to workers irrespective of their age ${ }^{13}$ :

\footnotetext{
${ }^{11}$ Only indicators based on demographic and employment data and not to the actual cost of public retirement pensions such as Bongaarts' (2004) public pension expenditure ratio are treated here.

${ }^{12}$ As illustrated by Bongaarts (2004) the PWR and the OADR are related, namely PWR= OADR x PR/ER, where PR is the pensioner ratio (the population aged 65 and older plus anyone under age 65 who is retired and over the minimum age of eligibility for a public pension) and ER the employment ratio (proportion of the population aged 15-64 that is employed).
} 
$R=\frac{\text { non-workers }}{\# \text { workers who perform remunerated work for } 1+\text { hours a week }}$

The authors argued for a better redistribution of work across all adult ages of life so individuals could combine work with education, leisure and childrearing as currently work is concentrated in the ages of life relevant for child-bearing and child rearing. Then, around the age of 60, people retire with decades left to live, which are paid for by younger working adults, many of whom are also taking care of children.

The 20th century also saw the rise of the eight-hour working day and five-day working week and a substantial reduction in the number of working days per year (through increased holiday entitlement), meaning that per capita yearly hours worked dropped by half (The Conference Board 2011; own calculation). One way to be more precise in capturing the impact of population ageing on the labour force size is to estimate full-time equivalent workers as the numerator. This is what Tyers and Shi (2007) did who constructed a 'NonWorking-aged' Dependency Ratio, which is the number of non-working persons over 60 per full-time equivalent worker, i.e.:

$N W D R=\frac{\text { non workers aged } 60+}{\text { full-time equivalent workers }}$

\subsection{Years Left-Based Elderly Dependency Ratios with Alternative Denominators}

In Spijker and MacInnes (2013b) it was also argued that only those in paid employment rather than everyone of 'working age' (however defined) should be considered as the population who is supposed to pay for elderly health and wellbeing. However, the authors then took Sanderson and Scherbov's (2007b) methodology for the numerator, i.e. by adjusting the age-threshold of the population considered 'old' for changing life expectancy at older ages, to obtain the so-called Real Elderly Dependency Ratio (REDR):

$R E D R=\frac{\# \text { men and women in ages with } R L E 15-}{\# \text { men and women in paid employment }} * 100$

In the example shown for the US in Figure 3, over the last 3-4 decades there was a decline in the population ageing burden, a trend which is expected to continue until the end of this decade after which the REDR is likely to increase, but slower than the POADR if we apply a $1 \%$ increase in LFP rates to ages 16-64 to attain rates similar to the recorded maximum for men in the year 2000 and well as for ages 65-69, 70-74 and 75+ in the anticipation of better health and incentives to work beyond retirement age.

\footnotetext{
13 This ratio is one of two, what the authors called, 'Rostock indicators' of Demographic Change. Their second indicator, abbreviated as $\mathrm{H}$, equals the number of hours worked per week per capita.
} 
Figure 3. POADR vs. REDR, including adjustments for changing LFP rates. US. 19502010.

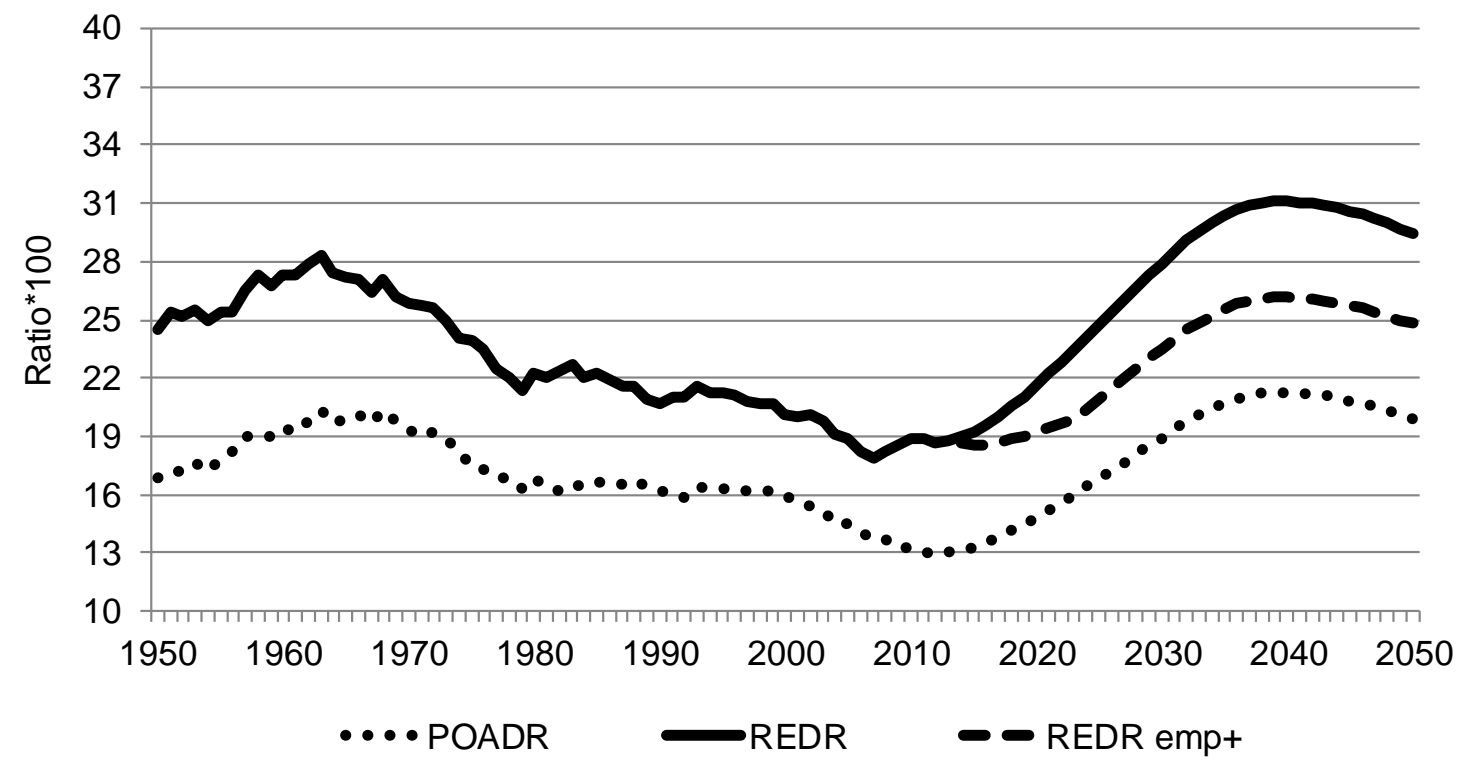

Data source: Sex-specific population and mortality data until 2011 come from the Human Mortality Database (www.mortality.org), the projected data from the US Census Bureau (www.census.gov) and the sex-specific employment data till 2013 form the Labour Force Statistics (www.bls.gov).

While the contribution of the REDR indicator in the discussion on alternatives to the OADR was to only consider people in paid employment instead of everyone of working age in the denominator, it considers everyone in paid employment as equally productive despite large time and country differences in terms of, for instance, hours worked. A potentially useful ratio would be therefore to divide the elderly population, defined as those in ages with RLE15-, by GDP, as recently illustrated in Spijker et al. (2014), i.e.

$R L E 15 / g d p=\frac{\# \text { men and women in ages with RLE15- }}{G D P \text { in } G K \$} * 1,000,000$

As a note, from a government policy perspective it makes no sense to use per capita GDP as we are interested in the total economic output, irrespective of the number of workers. If one wishes to analyse different countries at the same time it is best to use internationally comparative data on GDP such as the 1990 US\$ converted at Geary Khamis (GK) Purchasing Power Parities that can be obtained from The Conference Board (2014) Total Economy Database. To avoid very small numbers the ratio was multiplied by one million.

As the results showed in Spijker et al. (2014), again for the US, costs per elderly declined slowly but steadily between 1970 and around 2005, have been stable since then, and are expected to remain stable over the coming decades. As any government expenditure on the elderly has to come from taxes, we constructed a similar indicator to the previous one by dividing by government tax revenue:

$R L E 15 /$ tax $=\frac{\# \text { men and women in ages with } R L E 15-}{\text { tax revenue in } G K \$} * 1,000,000$ 
Here results showed that in the US the number of elderly per 1 million tax dollars declined from about 25 in the early 1970s to between 10 and 13 during the 2000s. Projecting this for the next 15 years the elderly/tax revenue ratio would be stable at around 10 elderly per 1 million tax dollars.

\subsection{Old Age vs. Ill-Health}

Another alternative used in population ageing indicators is not to consider life expectancy or TTD but disability (Sanderson \& Scherbov 2010). In a context of increasing proportions of elderly in high income/low mortality countries over the next decades, improvements in the functional status of elderly people could help mitigate the rise in the demand for, and hence expenditure on, long-term care. Lafortune and Balestat (2007) therefore analysed the trends in severe disability among the population aged 65 and over in 12 OECD countries. The authors defined severe disability as having one or more limitations in basic activities of daily living (ADLs) ${ }^{14}$ and considered it as an indicator of dependency because severe limitations tend to be closely related to demands for long-term care. They only found clear evidence of a decline in age-standardised and non-age-standardised disability rates among elderly people in five of the countries studied (Denmark, Finland, Italy, the Netherlands and the United States). Even in those countries, it was not expected that the declining trend would completely offset the rising demand for long-term care as a result of further population ageing that leads to increasing numbers of people at older ages with a severe disability. However, the authors did not contemplate comparing the trend in severe disability with, for instance, that of the employed population who indirectly finances the public health care of the elderly through taxation. This would have led to a 'severe' disability support ratio.

Manton et al. (2006) used a less stringent definition of disability ${ }^{15}$ to estimate the (change in the) proportion of active (i.e. disability-free) life expectancy (ALE) out of the total life expectancy (LE) at ages 65 and 85 between 1935 and 2080 in the $\mathrm{US}^{16}$ :

$$
A L E / L E \text { ratio }=\frac{\text { active life expectancy at age } x}{\text { total life expectancy at age } x} * 100
$$

Results showed that until the early 1980s total LE at age 65 grew faster or at the same pace as ALE, but since then (and at age 85 and older throughout the whole period) there has been an accelerated decline in disability, a trend that is expected to continue over the course of this century. This information was used by the authors to assess the long-term stability of the social security long-term liability. For instance, the growth in the latter could be slowed down by taking advantage of the increase in ALE by increasing the normal retirement age to

\footnotetext{
${ }^{14}$ Such as eating, washing/bathing, dressing, and getting in and out of bed.

${ }^{15}$ Any health-related difficulty performing at least one instrumental activity of daily living (IADL) of activity of daily living (ADL) for 90 or more consecutive days, or currently residing in an institution providing medical services.

${ }^{16}$ The authors used the Sullivan method of ALE estimation based on period life tables and survey-based periodspecific estimates of disability prevalence (Sullivan 1971).
} 
72 years by 2022 as this would give the same number of years of Social Security Old-Age Benefit (SSA) to the non-disabled retiree as in 1935 (SSA inception).

The application of disability-adjusted ageing measures to a large number of countries was first performed by Sanderson and Scherbov (2010) when they constructed the Adult Disability Dependency Ratio (ADDR) ${ }^{17}$.

ADDR $=\frac{\text { population } 20+\text { with disabilities }}{\text { population } 20+\text { without disabilities }} * 100$

This indicator was devised to measure the change in adult disability, whereby results show that the ADDR increase less rapidly than the OADR as well as the POADR. Although such information is useful for policymaking in health care, unlike the ALE/LE ratio this ratio is not strictly an EDR as the population in either side of the division line concerns the entire adult population. However, one could argue of course that people with a disability have an older age profile than those who do not.

Muszyńska and Rau (2012), on the other hand, proposed a health-state-specific (additive) decomposition of the OADR into an old-age healthy dependency ratio and an oldage unhealthy dependency ratio. These indicators could be seen as alternatives to the OADR that merely represents the weight of old people in relation to the population of working age irrespective of the health condition of those on either side of the equation. Indeed, the fact that poor health is the most important determinant of exit from paid employment in Europe while there is potential growth in the number of the elderly who are still in good health raises the question of whether potential improvements in health and disability could compensate for the ageing process on the labour supply side of the market. The authors' new indicators thus distinguish between a) the weight of those who are in good health and could potentially remain in the labour force; and b) those who are disabled or have chronic conditions, and are therefore less likely to work, and are more likely to require financial and other support, i.e.:

$$
\begin{aligned}
& H O D R=\frac{N_{\text {Healthy }, 65+}}{N_{15-64}} \\
& \text { UnHODR }=\frac{N_{\text {Unhealthy,65+ }}}{N_{15-64}}
\end{aligned}
$$

The sum of the two partial dependency ratios equals the OADR, i.e.

$\frac{N_{\text {Healthy }, 65+}}{N_{15-64}}+\frac{N_{\text {Unhealthy, } 65+}}{N_{15-64}}=\frac{N_{65+}}{N_{15-64}}=O A D R$

Using data from SHARE (Survey of Health, Ageing and Retirement in Europe - see www.share-project.org) the authors subsequently projected future disability rates for 13 European countries based on the following assumptions: a) that fertility and mortality levels will converge across countries by the year 2150 ; b) that morbidity will compress ${ }^{18}$, i.e. that

\footnotetext{
${ }^{17}$ With disability the authors referred to the proportion of people who responded in the EU-SILC survey that there were "strongly limited".

${ }^{18}$ The two other common scenarios of morbidity, the expansion of morbidity or the dynamic equilibrium were discarded by the authors because even under the more optimistic assumption, i.e. morbidity compression, it is generally expected that even the anticipated improvements in health and disability would not compensate for the ageing process on the labour supply (Muszyńska \& Rau 2012).
} 
the proportion of life spent in poor health will be smaller, but in contrast to Fries (1989), not by assuming fewer years of poor health and constant life expectancy but that unhealthy life expectancy does not change combined with increasing life expectancy at age 65; and that the age pattern of activity limitations will not change over the projection period.

Results showed that the growth in the number of elderly people in Europe is expected to cause a rise in both healthy and unhealthy dependency ratios but in which the healthy dependency ratio is projected to make up a larger part of the OADR (50\% in 2030 compared to $57 \%$ in 2006) due to the anticipated future improvements in population health and positive migration balance ${ }^{19}$. While from a policy perspective, especially with regard to future health care costs, it makes sense to split the elderly up into those who are considered healthy and those who are not, the authors used a fixed age threshold linked to retirement age to separate the working age (15-64) from the retired (65+), yet they acknowledge in discussion that many retire early (some, though not all, for health reasons). Neither did the authors adjust for proposed and implemented increasing pension ages in the respective European countries. So why not just perform the analysis on the retired population instead of using, what is increasingly becoming an arbitrary age, i.e. $65+$ ? Using the working age population, defined as anyone aged 15-64, as population who is supposed to finance the wellbeing of the elderly is also flawed. Firstly, using age 15 as the lower working age limit is no longer applicable, not only because education is compulsory until at least age 16 in all of the studied countries but many students continue several years beyond that to complete upper-secondary and tertiary qualifications. Secondly, and yet more significant, only about $66 \%$ of people in working age in the EU28 are actually in paid employment, whereby the rate for women at each age group is less than that of men and in most countries even less than half of men who are close to retirement age still do work. Neither does their second assumption regarding their optimistic scenario seem realistic, i.e. assuming that only those with activity limitations at older ages will be out of the labour market. How many healthy $80+$ would really want to continue to work? My suggestion would be to use those in paid employment as the denominator irrespective of age akin to the REDR indicator (formula 7) and make some simple assumptions as to future age-specific LFP rates based on current changes in pension systems. When considering the adult population as a whole as in the ADDR (formula 11), an alternative disability dependency ratio would be:

$R A D D R=\frac{\text { population } 20+\text { with disabilities }}{\text { population in paid employment }} * 100$

If we are instead only interested in elderly (whose age range corresponds to RLE15-) the formula equals:

$R E D D R=\frac{\sum_{s} \text { population } \text { with disabilities and RLE15- }}{\text { population in paid employment }} * 100$

\footnotetext{
${ }^{19}$ More precisely, compared to an OADR of 25 in 2006 in the 13 European countries where 11 elderly per 100 people of working age (15-64) were healthy and 14 unhealthy, the authors estimated that in 2030 the OADR would increase to 40 with exactly half of them in poor health and half in good health (Tables 1 and 3 in Muszyńska \& Rau 2012).
} 
In the event of a lack of internationally- or time-comparable data on disability, an alternative estimate of potential health care needs and expenditure is to use TTD of up to 5 years (i.e. using mortality rather than morbidity data as shown earlier in section 2.1). If we are then again interested in elderly, the dependent population equals that of POADR5TTD (formula 3), i.e.:

$R E D R 5 T T D=\frac{\# \text { men and women in ages with RLE15- \& TTD }<5}{\# \text { men and women in paid employment }} * 100$

This indicator — named the Health care need adjusted Real Elderly Dependency Ratiowas proposed in Spijker et al. (2014) where results for the US showed that like Prop RLE15\&TTD the health care burden has been very stable since around 1980 and will only slowly start to increase in a few years' time.

\subsection{Human Capital}

In order to alleviate the burden of increasing numbers of elderly in a population more productivity (as measured by GDP) is required. Up until now, some of the alternative dependency ratios took the actual working population into consideration in the denominator rather than the population of working age (formulas $4,5,7,14-16$ ) or the amount of hours worked (formula 6). Formula 8 did not consider the employed population at all but just took GDP, as from a government policy perspective total economic output is more relevant than the number of workers. On similar lines, as government expenditure is only possible through taxes, government tax revenue was used as the denominator in formula 9.

However, while productivity can be increased by getting more people to work, it can also be obtained through investing in human capital. Human capital not only improves the productivity of the labour force, it also stimulates long-term economic growth and can therefore facilitate the allocation of the resources required for the retired population (Kemnitz $\&$ Wigger 2000). One way society can invest in human capital is through education ${ }^{20}$; but while the prolongation of education beyond the current usual minimum age of 16 years has resulted in few young adults participating in the labour force, when higher educated persons do enter the workforce they quickly earn more money than lower educated workers of the same age. Hence, as more human capital leads to higher productivity, fewer workers are necessary to provide the financial resources that help to care for the 'dependent' elderly. In addition, it can alleviate some of the negative effects of population ageing as the most educated tend to work longer and retire at later ages and can therefore at least partially offset the shrinking working-age population (Lutz et al. 2008a; 2008b).

Yet, as Philipov et al (2014) argue, higher human capital also has a downside for government expenditure. This is because human capital that is utilized during working lives is decisive for the level of income obtained during retirement, i.e. it tends to be higher for

\footnotetext{
${ }^{20}$ Other ways include training and healthcare (Becker 2009) and, in the context of economic production, once employed further human capital is accumulated through experience.
} 
individuals who earned more during their working life. They therefore constructed an EDR that takes into account the increasing human capital in both the working and retired-age population. Specifically, and building on Striessnig and Lutz (2014) who applied educationweighted dependency ratios with the purpose to determine the optimal fertility needed to achieve the lowest total dependency ratio, the authors weighted the working-age population by earning functions and the elderly population by human-capital-specific public pension levels. To arrive at their dependency ratio, in the first step the authors projected the age, sex and education composition of the population, whereby each individual contributed exactly one unit to the overall distribution. Subsequently, they differentiated the units according to the achieved level of human capital, applying education- and sex-specific earning functions to the working-age population (ages 20-64). Under the assumption that labour income is positively correlated with schooling and work experience, this was done by linking each level of education with an average number of years spent in school; and linking work experience with age: the higher the age, the longer the work experience. However, as according to the authors human capital accumulation could decline at the end of working life, the (full-time gross) income function levels off towards old working ages or takes the form of an inverse Ushape:

$Y=\alpha$. Education $+\beta_{1} \cdot$ Age $+\beta_{2}$ Age $*$ Age $+\varepsilon$,

The resulting income functions were then used to construct a population aged 20-64 that is adjusted for its human-capital and age-specific composition. This was one by pivoting all values to the lowest income, which was that of a female aged 20 having a low education. If she contributed 1 unit to the age composition, a man aged 50 contributed 2.2, 2.87 or 4.72 units if his level of education was low, middle or high, respectively.

The human-capital composition of the population aged 65 and above was constructed differently as Philipov et al (2014) assumed that this population is retired, so the retired human capital was examined. To this end, they made use of the median of education-specific gross public pensions over the whole age span 65 and above. The person-units assigned to a person aged 65 or older with a specific sex and education were once more related to the income of a female aged 20 having an education equal to or lower than secondary level. The resulting ratio they called the human capital-specific OADR or HC-OADR:

HC-OADR $=\frac{\text { population } 65+\text { adjusted for education-specific median gross public pensions }}{\text { population } 20-64 \text { adjusted for age,education and gross income }}$

Based on the results the authors concluded that while education has a positive impact on an economy's productivity, in the long run a constant or moderately growing human capital may actually aggravate the consequences of population ageing rather than alleviate them as a better educated labour force will have higher pensions once it has retired because they contributed more during their working life. The authors therefore advocated integrating human capital into the calculation of the conventional population age composition and dependency ratio as an increase in education accelerates population ageing. However, while their robustness checks (e.g. excluding the unemployed, different fixed or increasing ages at retirement) did not alter the results, the authors did not contemplate adjusting the 
denominator for employment (e.g. by taking full-time equivalent workers), as participation rates continuously change in the wake of economic booms and busts. Likewise, as educational expansion has led to an increase in female LFP and participation rates of the young-old have begun to increase over the last decades, there are likely to be proportionally more older workers in future. The authors' rationale for deriving their income functions for full-time employment but assigning them to the entire working-age population rather than only the employed was because such estimates present the full productive capacity of employment and health/disability status. However, this raises the question as to how applicable or useful their indicator really is, especially for international and time comparison, given that such an assumption does not reflect reality. For instance, the proportion of the working-age population in western countries that does not work fluctuates between about 20\% (Japan 2012) and 55\% (Spain 1985) (www.oecd.org). Moreover, educational attainment is not a guarantee for employment as has been evident in Spain for decades. Youth unemployment in 2014 was still above 50\% while the proportion of 20-34 year olds with tertiary educational attainment in 2013 was well above the EU28 average (http://ec.europa.eu/eurostat/data/database).

\subsection{Capturing Changes in Age-Specific Production, Consumption and Wealth}

Proponents of the doom scenario that population ageing will bring a decline or stagnation in future economic productivity tend to forget that the ratio of productive workers to dependent citizens has been driven down, particularly over the last half a century or so, by the shortening of workers' labour market careers due to the need for a higher educated labour force and, especially during the 1980s and 1990s, through early retirement schemes (Spijker \& MacInnes 2013a). Although baby boomers did of course dominate the workforce, and were an important factor in the first demographic dividend, as explained in more detail below, the economy also grew in western countries because it became orientated towards more productive industries and high-value services. Less well known (at least for non-economists), however, is that economic growth is also driven by consumption and savings, that together with aggregate labour supply and productivity, tend to vary depending on where most people fall in the life cycle.

Not surprisingly, labour supply is higher among working-age adults than among the young and old. Conversely, the ratio of consumption to production tends to be greater than 1 for the economically dependent youth and elderly and less than 1 for the working age as the overwhelming majority of the former are not in paid employment while money is spent on, respectively, education and healthcare (Figure 4). As a consequence, and other things equal, a country with large age-groups of youth and elderly is likely to experience slower growth than one with a high proportion of working-age people (Coale \& Hoover 1958). At the same time, as the older population becomes larger and politically stronger, adopting certain policies such as cutting health and pension benefits will prove difficult. This worries policymakers and economists who argue that without reforms the sustainability of public pensions and health care is threatened. However, if policymakers initiate action early, a country will be better able to deal with the social, economic, and political effects of an impending altered population structure. A good moment would be during the intermediate phase of the demographic 
transition when population ageing is barely noticeable and the first demographic dividend is being materialised as the working-age population outgrows the number of consumers and income per effective consumer grows faster than productivity (Bloom et al. 2010).

Under these circumstances population ageing can actually have potentially positive economic outcomes in the form of a so-called second demographic dividend, i.e. that consumption outgrows the growth in the economic support ratio. But as with the first demographic dividend, capturing this potential depends on whether consumers and policy makers are forward-looking and respond effectively to the demographic changes that are coming, as reflected by the quality of governmental institutions, labour legislation, macroeconomic management, openness to trade, and education policy (Mason \& Lee 2006; Bloom \& Canning 2008) ${ }^{21}$. Some of the additional resources that are freed during the first demographic dividend can be used to increase consumption, raising current standards of living, and some can be invested in human or physical capital or in stronger institutions that will lead to permanently higher economic growth.

Figure 4. Consumption and labour income age profiles for the United States, 2003.

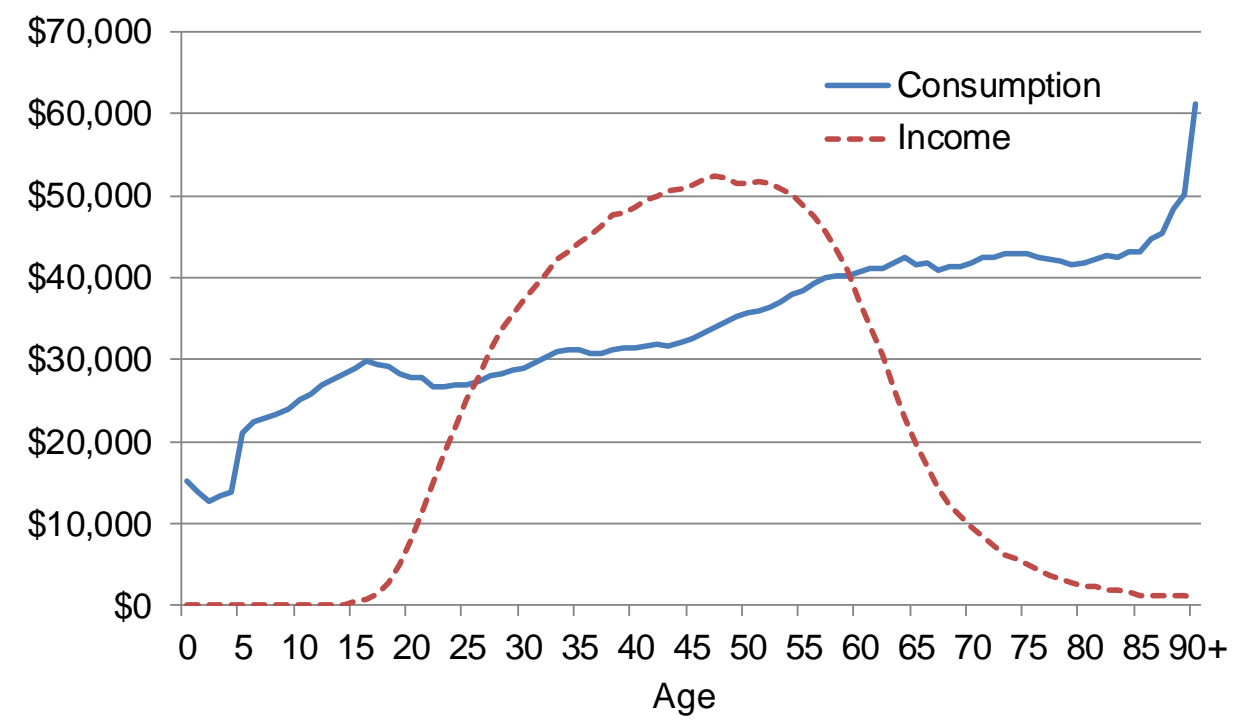

Source: National Transfer Accounts project (www.ntaccounts.org).

In a sense, the two dividends are opposite sides of the same coin. The first dividend arises because parents of working-age have fewer (dependent) children and the second dividend because one generation later, the older, mostly retired, parents will have fewer working-age children. The share of elderly in the total population therefore increases, exacerbated by improved old-age survival chances. Importantly, however, is that while the second dividend is a consequence of population ageing, the accumulation of wealth occurs in

\footnotetext{
${ }^{21}$ An example where such conditions were often absent and therefore the economic performance lagged well behind that of East and South East Asia, despite having similar demographics, is Latin America during the period 1965-1990 (Bloom \& Canning 2008).
} 
anticipation of ageing. The first and second dividends may therefore also overlap as early policy response is essential to realizing the second dividend (Mason \& Lee 2006).

Specifically, during the first demographic dividend the growth in the effective labour force $(L)$ is greater than the effective number of consumers $(N)$, i.e. a positive support ratio (SR). Depending on data availability different support ratios $(L / N)$ can be calculated, but most methods can be traced back to the publication by Cuttler et al. (1990). For instance Prskawetz and Sambt (2014) applied so-called National Transfer Account ${ }^{22}$ (NTA) age profiles for labour income and consumption to obtain $\mathrm{L}$ and $\mathrm{N}$ and the resulting NTA support ratio. In the simplest form the same weights are given to all consumers (of all ages) and all producers (fixed at ages 20-64) (i.e. SR1 $=L 1 / N 1$, which thus equals the inverse of the TDR). However, it is more realistic that age groups differ in labour productivity given the age differences in human capital, income, LFP and hours worked, and in consumption needs, such as in relation to private non-medical expenses, public education expenses and medical expenses. This leads to the following adjusted support ratio:

$S R 2(t)=\frac{L 2(t)}{N 2(t)}=\frac{\sum_{a=0}^{\omega} \gamma(a) N(a, t)}{\sum_{a=0}^{\omega} \alpha(a) N(a, t)}$

where $N(a, t)$ represents the number of people aged $a$ in year $t ; \gamma(a)$ represents an agespecific, time-invariant vector of productivity that is based on the NTA age profile of labour income scaled by the unweighted average of labour income between 30-49 years of age $\mathrm{e}^{23}$. Similarly, $\alpha(a)$ represents an age-specific, time-invariant vector of consumption that is based on the NTA profile of consumption, scaled again by the unweighted average of labour income between ages 30 and 49. Finally, $\omega$ denotes the maximum length of life (Prskawetz \& Sambt 2014).

The first demographic dividend is then represented by the growth rate (denoted by ' ' ') of the SR. If positive, i.e. when the effective number of producers is growing faster than the effective number of consumers, a dividend is obtained ${ }^{24}$ :

$S \widehat{R 2(t)}=\widehat{L 2(t)}-\widehat{N 2(t)}=\widehat{L_{N}}$

\footnotetext{
${ }^{22}$ Motivated by the economic life cycle, National Transfer Accounts provides a systematic and comprehensive approach to measuring the economic flows from a generational perspective. Given that at the beginning and end of our lives we consume more than we produce through our labour and during the mid-part of our lives it is the other way around, in the context of population ageing, changes in population age structure influence saving and the demand for wealth and capital, such as the demand for old-age support. Specifically, NTA provide an accounting of economic flows to and from residents of a country classified by their age. The accounts are comprehensive in that all economic flows that arise as a consequence of the production of goods and services during the year are incorporated into the accounts as well as age reallocations realized by relying on intergenerational transfers and assets. It is therefore a new tool that can be used to gain greater insights about how standard of living, generational equity, financial conditions and other important features of our economies are likely to be influenced by these demographic changes (UN 2013a).

${ }^{23}$ Normalising on the per capita labour income of persons aged 30-49 is a standard approach in NTA analyses for comparing the results across countries (see Prskawetz \& Sambt (2014) and Mason \& Lee (2011)).

${ }^{24}$ However, Crespo Cuaresma (2014b) found that not the higher proportion of workers but improvements in educational attainment are key to explaining productivity and income growth, i.e. a substantial portion of the demographic dividend is an education dividend. It is also important to note that changes in the SR ignore changes in unemployment and labour force participation rates, which are kept constant in the NTA profile as they are computed per person for the base year only (Patxot et al. 2011).
} 
According to a study by Mason and Lee (2006) the world as a whole and most major regions experienced a favourable first demographic dividend between 1960 and 2000 (an exception being the least developed countries located primarily in Africa). Particularly some of the high performing countries of East Asia enjoyed a very favourable dividend as the effective labour growth outgrew the rate of increase in effective consumers. However, both there as in Europe (though not Northern America) population ageing is likely to cause a negative first dividend over the coming decades (Table 3). In the world's most aged countries such as Spain this is already taking place (Figure 5).

Table 3. First demographic dividend, 1960-2050. Major regions of the world.

\begin{tabular}{|c|c|c|c|c|c|c|c|c|}
\hline & \multicolumn{2}{|c|}{$\begin{array}{c}\text { Annual growth rate (\%) } \\
1960-2000\end{array}$} & \multirow{2}{*}{$\begin{array}{c}\text { First } \\
\text { divided } \\
(\%) \\
1960- \\
2000\end{array}$} & \multicolumn{2}{|c|}{$\begin{array}{c}\text { Annual growth rate (\%) } \\
2000-2050\end{array}$} & \multirow{2}{*}{$\begin{array}{c}\text { First } \\
\text { dividend } \\
(\%) \\
2000- \\
2050\end{array}$} & \multicolumn{2}{|c|}{$\begin{array}{l}\text { Cumulated first divi- } \\
\text { dend since } 1960(\%)\end{array}$} \\
\hline & $\begin{array}{c}\text { Effective } \\
\text { labour force }\end{array}$ & $\begin{array}{c}\text { Effective } \\
\text { consumers }\end{array}$ & & $\begin{array}{c}\text { Effective } \\
\text { labour force }\end{array}$ & $\begin{array}{l}\text { Effective } \\
\text { consumers }\end{array}$ & & 2000 & 2050 \\
\hline WORLD & 1.99 & 1.80 & 0.19 & 0.89 & 0.71 & 0.18 & 7.7 & 16.0 \\
\hline More developed regions & 0.90 & 0.71 & 0.18 & -0.56 & -0.27 & -0.29 & 7.6 & -4.3 \\
\hline Less developed regions & 2.42 & 2.17 & 0.25 & 1.19 & 0.91 & 0.29 & 10.3 & 23.7 \\
\hline Least developed countries & 2.42 & 2.51 & -0.09 & 2.95 & 2.27 & 0.67 & -3.5 & 26.2 \\
\hline Northern America & 1.40 & 1.14 & 0.25 & 0.36 & 0.55 & -0.19 & 10.6 & 2.5 \\
\hline Europe & 0.65 & 0.51 & 0.14 & -1.00 & -0.69 & -0.32 & 5.8 & -6.9 \\
\hline Oceania & 1.90 & 1.72 & 0.18 & 0.89 & 0.86 & 0.03 & 7.4 & 8.5 \\
\hline Asia & 2.30 & 2.01 & 0.29 & 0.77 & 0.58 & 0.19 & 12.3 & 21.2 \\
\hline Latin America & 2.62 & 2.27 & 0.35 & 0.91 & 0.65 & 0.26 & 15.0 & 27.5 \\
\hline Africa & 2.60 & 2.66 & -0.06 & 2.74 & 2.03 & 0.71 & -2.2 & 29.8 \\
\hline China & 2.27 & 1.78 & 0.49 & -0.23 & -0.06 & -0.18 & 21.5 & 13.2 \\
\hline Republic of Korea & 2.49 & 1.74 & 0.74 & -0.49 & -0.04 & -0.45 & 34.7 & 12.5 \\
\hline
\end{tabular}

Source: Mason and Lee (2006).

Figure 5. First demographic dividend, 1950-2050. Spain.

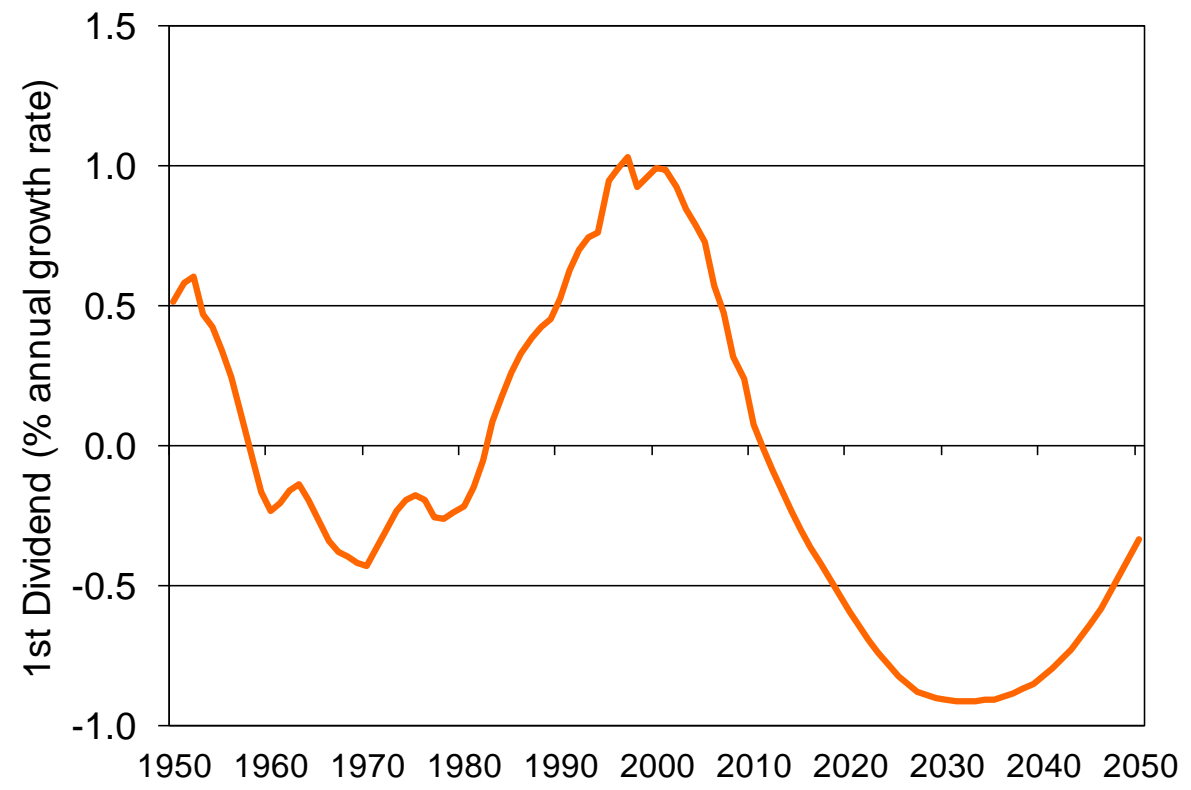

Source: adapted from Patxot et al. (2011). 
On the other hand, longer life and changes in the population age structure can lead to more rapid accumulation of assets and thereby produce a second demographic divided. However, for this to take place current per capita consumption needs to rise by less than the support ratio as saving rates as well as assets will increase. This then leads to an increase in labour productivity and wages and in the long run a sustained higher level of consumption. Specifically, the second demographic dividend can be formally derived starting from the following decomposition of consumption per capita (Mason \& Lee 2007):

$\frac{C(t)}{N(t)}=\frac{C(t)}{Y(t)} \cdot \frac{Y(t)}{L(t)} \cdot \frac{L(t)}{N(t)}$

where $C(t)$ denotes total consumption and $Y(t)$ is total labour income. Note that $L(t)=L 2$ and $N(t)=N 2$ from equation (a) with $L(t) / N(t)$ equalling the SR. The term $C(t) / N(t)$ is denoted as consumption index $\bar{c}(t)$, while $Y(t) / L(t)$ is considered the labour market index $\bar{y}(t)$. If the first two product terms on the right hand side of (18) were not affected by demographic change, a change in the support ratio would translate into a proportional change of consumption per capita. However, as was argued in Mason and Lee (2007), a change in the age structure of a population will also affect the consumption per output level $(C / Y)$. If $C / Y$ decreases when the SR increases, savings will increase. Following Prskawetz and Sambt (2014) by rearranging equation (b), writing it in growth terms and using subscripts to denote the numerator of the variable under consideration, one obtains the rate of growth of consumption relative to income $\hat{C}_{Y}$, i.e. the second demographic dividend:

$\hat{C}_{Y}=\left(\hat{C}_{N}-\hat{Y}_{L}\right)-\hat{L}_{N}$

The growth rate of $L_{N}$ equals the first demographic dividend, while the term in brackets gives the "extent to which consumption per consumer $C_{N}$ rises relative to productivity changes $Y_{L}$ induced by technological innovation" (Mason \& Lee 2007). However, the second dividend is more complex to estimate than the first. This is partly because the accumulation of wealth is intrinsically forward looking as individuals accumulate wealth in anticipation of future needs to support consumption, to finance bequests, and to respond to other uncertain events. In other words, current generations must first reduce their consumption in order to increase their wealth and achieve higher consumption in future periods. This therefore means that projections of the equivalent number of consumers and producers for each cohort and complete life cycle wealth estimates for many decades in advance are required; and while population projections are often uncertain, life cycle wealth data are often not available. Fortunately, the nature of the economic lifecycle provides assistance with this problem as for the most part, capital accumulation is concentrated among older working-age adults who are approaching their peak earnings and have completed their childrearing responsibilities, reason why it is recommended to use wealth held by those age 50 and older to measure the effect of demography on aggregate lifecycle wealth and the second demographic dividend (Mason 2005). Given this age-profile, each can be considered as ageing indicators.

Specifically, aggregate lifecycle wealth, $W(t)$ is the wealth that adults must hold, as a group in year $t$ in order to achieve a given path of consumption and labour over the remainder of their collective existence. $W(t)$ is equal to the present value, $P V$, of the consumption less the $P V$ of the labour income of those over the remainder of their lives, i.e. 
$W(t)=\sum W(a, t)=\sum(P V[C(a, t)]-P V[Y(a, t)])$

where $C(a, t)$ and $Y(a, t)$ are vectors of current and future consumption and current and future labour income, respectively, for the cohort of age $a$ and year $t$. Summing $W(a, t)$ across all adult ages in year $t$ yields aggregate lifecycle wealth, $W(t)$ (Mason \& Lee 2007).

This wealth can take different forms. One possibility is that retirees will rely on transfers from public pension and welfare programmes $T_{p}(t)$ or from adult children $T_{k}(t)$ and other family members. In this case, individuals are accumulating transfer wealth as a method of financing consumption during their retirement years. A second possibility is that individuals will accumulate assets and capital $A(t)$ such as private savings and funded pensions during their working years and that this capital will serve as the source of support during the retirement period. Both of these forms of wealth can be used to deal with the life cycle deficit at older ages. The second demographic dividend thus depends on (a) the share of family transfers to children $\tau_{k}(t)=T_{k}(t) / W(t)$ and (b) on how much of the old age consumption is supported by transfers as opposed to assets $\tau(t)=\frac{T_{P}(t)}{A(t)+T_{P}(t)}$ (where $A(t)+$ $T_{P}(t)$ is denoted as pension wealth). The higher the share of family transfers to children (as opposed to public transfers) the more wealth is required from people for financing consumption of their children. Analogously, if elderly finance a large share of their consumption through asset based reallocation, people need to accumulate more wealth during their active life for the time of retirement (Prskawetz \& Sambt 2014). Likewise, for the macroeconomy it is important whether that wealth is created by expanding transfer programs or accumulating assets because only in the latter case will savings and capital deepening increase (Mason \& Lee 2007).

Mason (2005) estimated first and second dividends over the last three decades of last century and compared it with the growth in GDP per capita (Table 4). He found that the second demographic dividend was already larger than the first in all major world regions, but that only in industrial countries, East Asia \& Southeast Asia and South Asia the two dividends combined were less than the total growth in GDP per capita. However, while changes in the age composition accounted for an important part of the rapid growth in East and Southeast Asia, other regions such as Latin America did not successfully exploit their demographic dividends as actual growth fell well short of that opportunity, although in Africa the dividend period is just beginning.

It is, however, important for ageing societies to know that the way a society supports its elderly determines how much of the second demographic dividend is realised, while combining the two demographic dividends could be used as an indicator of ageing. For instance, a positive total dividend is not anticipated in most European countries over the coming decades because the consumption of the elderly is predominantly financed through familial and public transfers rather than assets. If transfer wealth dominates the age reallocation system for supporting the elderly it would mean that no second demographic dividend is yielded (Mason \& Lee 2006). This is because an increase in transfer wealth will crowd out the stock of capital and hence future economic growth and per capita income will decline. 
Table 4. Estimates of the first and second dividends and the actual growth in Gross Domestic Product per effective consumer (GDP/N). 1970-2000.

\begin{tabular}{lccccc} 
& \multicolumn{3}{c}{ Demographic Dividends } & Actual \\
\cline { 2 - 4 } & First & Second & Total & $\begin{array}{c}\text { GDP growth- } \\
\text { GDP/N }\end{array}$ & $\begin{array}{c}\text { Dividend } \\
\text { Industrial }\end{array}$ \\
East Asia \& Southeast Asia & 0.34 & 0.69 & 1.03 & 2.25 & 1.22 \\
South Asia & 0.59 & 1.31 & 1.90 & 4.32 & 2.42 \\
Latin America & 0.10 & 0.69 & 0.80 & 1.88 & 1.08 \\
Sub-Saharan Africa & 0.62 & 1.08 & 1.70 & 0.94 & -0.76 \\
Middle East and North Africa & -0.09 & 0.17 & 0.08 & 0.06 & -0.02 \\
Transitional & 0.51 & 0.70 & 1.21 & 1.10 & -0.11 \\
Pacific Islands & 0.24 & 0.57 & 0.81 & 0.61 & 0.20 \\
\hline
\end{tabular}

Source: Mason (2005)

To conclude, Table 5 provides an overview of the alternative ageing indicators that have been discussed in the paper, including the direction of estimated short-term future trends. 


\section{Table 5. Inventory of indicators of population ageing as alternative to the Old Age Dependency Ratio (OADR)}

\# Abbrev. Full name of indicator Measured as

The standard

0 OADR Old Age Dependency Ratio

Years left vs. years lived

1. Prop RLE15- Proportion of pop in age groups with RLE15-

2. POADR Prospective Old Age Dependency Ratio

3. POADR5TTD Health care need adjusted POADR

Non-working to working population ratios
4. PWR
Pensioner/Worker Ratio
5. $\mathrm{R}$
Ratio Nonworkers to Workers
6. NWDR
Non-Working Aged Dependency Ratio

$\begin{array}{ll}\text { 7. REDR } & \text { Real Elderly Dependency Ratio } \\ \text { 8. RLE15/gdp } & \text { Elderly to GDP Ratio } \\ \text { 9. RLE15/tax } & \text { Elderly to Tax Ratio }\end{array}$

Years left-based elderly dependency ratios with alternative denominators $\frac{\text { population } 20+\text { with disabilities }}{\text { population in paid employment }} * 100$

Short-term Main reference

Prediction*

$\frac{\sum_{s} \text { population } R L E 15-}{\text { totalpopulation }} * 100$

total population

$\sum_{\text {s population RLE15- }}$

\# men and women in age groups with RLE15- $2 T T D<5-* 100$

$\frac{\# \text { men and women in age groups with RLE15- \& TTD }<5}{\text { population } 20+\text { up to age at which } \sum_{\text {s }} \text { population RLE15- }} * 100$

Pensioners

$\overline{\text { population in paid employment }}$

Non-workers

$\overline{\text { Workers remunerated for } 1+\text { hour per week }}$

non-workers aged $60+$

$\frac{\text { full-time equivalent workers }}{\text { non }}$ $\uparrow$ but $<$ OADR

$\uparrow$ but $<$ OADR

Slight $\uparrow$

$\uparrow \approx$ OADR

$\uparrow 2005-25$

$\uparrow \approx \mathrm{OADR}$

Slight $\downarrow$

Constant

Constant e.g. UN $2013 b$

Sanderson \& Scherbov 2007b

Sanderson \& Scherbov 2007b

Spijker et al. 2014

Bongaarts 2004

Vaupel \& Loichinger 2006

Tyers \& Shi 2007

Spijker \& MacInnes 2013b

$\frac{\# \text { men and women in ages with RLE15- }}{\text { GDP in GK } \$} * 1,000,000$

\# men and women in ages with RLE15- $* 1,000,000$ tax revenue in $G K \$$
Spijker et al. 2014

Spijker et al. 2014 
Old age vs. ill-health dependency ratios

10. ALE/LE Ratio Active (disability free) LE to total LE

11. ADDR Adult Disability Dependency Ratio

12. HODR

Healthy Old-age Dependency Ratio

13. UnHODR

Unhealthy Old-age Dependency Ratio

14. RADDR Real Adult Disability Dependency Ratio

15. REDDR Real Elderly Disability Dependency Ratio

16. REDR5TTD Health care need adjusted REDR

\section{Human capital-based elderly dependency ratio}

\section{HC-OADR Human capital OADR}

Consumption vs. production ratios and lifetime wealth
$18 \hat{L}_{N}$
First Demographic Dividend

$19 \hat{C}_{Y}$

Second Demographic Dividend

$20 W(t)$

Aggregate Lifecycle Wealth $\frac{\text { active life expectancy at age } x}{\text { total life expectancy at age } x} * 100$

$\frac{\text { population } 20+\text { with disabilities }}{\text { population } 20+\text { without disabilities }} * 100$

$N_{\text {Healthy, } 65+}$

$N_{15-64}$

$\frac{N_{U n h e a l t h y, 65+}}{N_{15-64}}$

$\frac{\text { population } 20+\text { with disabilities }}{\text { population in paid employment }} * 100$ $\frac{\sum_{s} \text { population with disabilities and RLE15- }}{\text { population in paid employment }} * 100$

$\frac{\# \text { men and women in ages with RLE15- \& TTD }<5}{\# \text { men and women in paid employment }} * 100$

* For most low-mortality countries. If possible, comparison in projected trend with other indicator.

** The formula is here simplified. For a full account of how life cycle wealth can be estimated, see Mason and Lee (2007). 


\section{Discussion}

Old-age survival has been improving virtually without interruption over the last half century in high income countries. Yet we continue to measure elderly in the same static manner today as 50 years ago, despite the diverse employment histories, social responsibilities, financial circumstances and health statuses. Sixty-five is often taken as the demarcation line between mature adulthood and old age, largely due to the fact that for many years it has been, or was until recently, the statutory retirement age. However, a contested conjecture is if 65-year-olds today are really as old as 65-year olds in 1965, or even in 2000, even if they lived the same number of years (Lutz et al. 2008c). This conjecture is fundamental because we live in an era where most people in low-mortality countries are expected to survive beyond 80 years of age while concomitantly current retirees stop working (well) before the pension eligibility age. Over the last few decades this has raised issues regarding the affordability of old-age social security benefits and medical, health and personal care. Today, this concern is becoming even more urgent as baby boomers are starting to retire and smaller birth cohorts are making up a larger part of the current, and more importantly, future workforce as fertility rates have been just or well below replacement in most Western countries for 3-4 decades. On the other hand, there are with regard to the workforce also two counter-trends: in many countries proportionally more women are in paid employment today than ever before while there are also signs that the LFP rate of older workers is increasing.

Not surprisingly, while some concerns regarding the impact that population ageing will have on society are justified, much of the rhetoric is based on the use of elderly dependency ratios such as the OADR that do not consider changing old-age survival rates, labour force participation rates or consumption and savings patterns. As a result, over the last 10 years or so, particularly demographers have looked at developing alternative indicators of population ageing. Perhaps the most important conclusion deriving from this inventory is that the indicator to use depends on the purpose of the exercise.

While this may appear to be obvious, the OADR or the proportion of the total population aged $60+$ or $65+$ is still used as the basis for arguments concerning the supposed negative effects of population ageing and even for policy changes. I have therefore grouped the alternative indicators that were discussed in this paper into five types:

1. Purely demographic

2. Purely economic

3. Demographic and economic related

4. Health and disability related

5. Based on human capital

This paper has shown that the best way to investigate the possible effects of population ageing on economic variables such as consumption, savings and productivity or the affordability of the public pension system types 2, 3 or 5 indicators should be used. If, on the other hand, one aims to study changes in elderly health and disability in the context of the 
sustainability of the public health care system then types 1 and 4 are the most obvious ones to choose from.

What population ageing means for future economic growth and public finances have been of particular interest for academics. Recent literature has developed theoretical arguments that focus on the different channels through which demography may influence economic growth, as well as empirical evidence on the potential effects of such demographic changes on several macroeconomic variables (Crespo Cuaresma et al. 2014a). This has been aided by the creation of the National Transfer Accounts that has enabled a more precise construction of population ageing indicators by taking into consideration the effect of changes in the population age structure on income and consumption flows. One result of NTA is for instance that population ageing also depresses the support ratio after adjusting for age-specific consumption and labour income profiles and is likely to produce a negative first demographic dividend in most industrialised countries over the coming decades (Prskawetz \& Sambt 2014). The resulting increasing proportion of non-working elderly in the population is, as we know, a common political and economic worry because it is thought that the burden for working adults of financing the consumption of non-working adults through public transfers will increase to unsustainable levels (e.g. European Commission 2010). However, detailed age accounting for individuals and households using NTA data has also shown that basing policy solely on expected changes in the support ratio is ignoring an array of other factors that, under the right circumstances, may actually produce a second demographic dividend in ageing populations. This is for several reasons. First, because retirees do not, as popular discourse may suggest, rely exclusively on the labour of others (through public and familial transfer systems) to fund their pensions but also on their own pension funds, personal savings, homes acquired during their working years, and other assets to finance some part of their retirement (Mason \& Lee 2007). Secondly, during the process of population ageing the labour force increasingly concentrates in higher age groups. As they are generally aware of their own mortality risk (Hamermesh 1985; Post \& Hanewald 2012) they know that they will spend more years in retirement than earlier cohorts. This can be a strong incentive for people to accumulate assets for their retirement, which then leads to an upward shift in the age profile of wealth, an important source of the second demographic dividend.

However, when consumption of the elderly is mainly financed by the state through public transfers (e.g. state pensions), as in many European countries, a positive second demographic dividend may be harder to achieve. Economic and policy responses to population ageing and population decline therefore holds the key to continued economic growth for many countries, but this will not be an easy task as many issues will need to be considered. According to Clark et al. (2007) such include whether:

- governments should be concerned about economic growth or only focus on per capita income and consumption;

- taxes will need to be raised, benefits cut, retirement ages raised for the financing of national retirement systems and if governments can make the transition from current payas-you-go plans to funded plans;

- policies should be adopted to curtail rapid growth in health care spending; 
- there was a first demographic dividend (due to declines in child dependency) and if a country can produce a second demographic dividend (save now to increase production in the future);

- LFP rates can be increased to maintain the size of the labour force (e.g. by facilitating women to enter the workforce, relaxing immigration standards, keeping older workers in the workforce).

These issues make it clear that elderly dependency or support ratios are required that don't merely compare a supposed dependent population defined by a fixed age (usually aged 65+) with everyone of working age as such are misleading because they do not take other important factors into consideration. Depending on the context, the picture of population ageing may be quite different than that is often suggested on the basis of the OADR. For instance, the population ageing that many populations will experience over the coming decades shifts the demand for wealth and capital to the right, leading to increased capital per worker, and therefore higher, not lower productivity, while consumption is also higher in the long term. Likewise, focussing on public pensions also gives a mistaken sense of the consequences of rising old-age dependency as they only cost a small fraction of national output. Support ratios that take into consideration age-specific consumption and production patterns are therefore much more realistic than the standard OADR (Lee \& Mason 2010).

Moreover, the supposed "dependency burden" of the elderly is a function of the institutional welfare system that is in place rather than an elderly to worker ratio. For instance, if the only reason to raise the pension age are budgetary considerations that cannot cover an increasing proportion of elderly it is unclear why alternative expenditure reductions or revenue increases are not equally satisfactory. As Scherbov et al. (2014) state, a better rationale for raising pension ages is that pensioners are living longer so it would be unfair for younger generations to have to pay for the older generations' longevity gains. Older generations enjoying those gains should therefore help to keep public pensions affordable by increasing their LFP during their working life and/or retiring later ${ }^{25}$.

Although dealing with the issues raised by Clark et al. (2007) is obviously beyond scope of this paper, the use of adequate population ageing measures would absolutely facilitate estimating the supposed "dependency burdens" for different types of population ageing issues. For instance, in terms of health care this paper introduced several indicators that approximated the dependent population by according to a particular characteristic other than simply taking the entire $65+$ population. One was to consider the proportion of the population with an average life expectancy of 15 years or less (RLE15-) as the numerator with the argument that elderly of a particular age generally have higher remaining life expectancies and are healthier than their counterparts in earlier generations (Sanderson \& Scherbov 2013) and with similar differences between low and high mortality countries. This way, a more comparable elderly population in terms of health needs is obtained. It formed the basis for

\footnotetext{
${ }^{25}$ According to estimates made by Scherbov et al. (2014), in most European countries an increase in normal pension age to 68 by 2050 would not be enough to keep the burden on the working population from ballooning and may require the pension age to be increased to 70 years, unless LFP increases by several percentage points.
} 
Sanderson and Scherbov's (2007b) Prospective Old Age Dependency Ratio, while Spijker and MacInnes (2013b) subsequently adjusted the denominator with the argument that the bulk of health care is paid by those in paid employment. However, further refinements can still be made because health care costs are more related to factors such as progress in medical knowledge and technology, hospitalization costs and more use of long-term care facilities rather than population ageing, costs that are particularly high during the last few years rather than the last 15 years of a person's life (see section 2.1 for references). Sanderson and Scherbov's RLE15- definition of elderly is a good way to define the older population, but those who form part of the population who actually require health care is only a subset of this population. The "Health care need adjusted Real Elderly Dependency Ratio" (i.e. considering within this population those elderly who are expected to die within 5 years) was one attempt to adjust this further.

To conclude, population ageing is the result of changes in the age distribution that has led to proportionally more elderly in the population. Due to the widespread use of inadequate population ageing indicators such as the OADR this phenomenon is often seen as a threat to economic growth and government budgets spending even though many other factors are involved in the observed and projected increases in health care and social benefit spending or economic production. Indeed, an ageing population even has the potential for economic growth with the right policies in place. However, a more widespread use of more precise population ageing indicators is still required in order to get the general public, policy makers and even some academics to also understand this. 


\section{References}

Baltes PB, Smith J (2003) New Frontiers in the Future of Aging: From Successful Aging of the Young Old to the Dilemmas of the Fourth Age. Gerontology 49:123-135.

Becker GS (2009) Human capital: A theoretical and empirical analysis, with special reference to education. University of Chicago Press, Chicago

Bíró A (2010) Subjective mortality hazard shocks and the adjustment of consumption expenditures. Journal of Population Economics:1-30.

Bloom DE, Canning D (2008) Global Demographic Change: Dimensions and Economic Significance. Population and Development Review 34:17-51.

Bloom DE, Canning D, Fink G (2010) Implications of population ageing for economic growth. Oxford Review of Economic Policy 26 (4):583-612.

Bongaarts J (2004) Population aging and the rising cost of public pensions. Population and Development Review 30 (1):1-23.

Brouard N (1986) Structure et dynamique des populations. La pyramide des années à vivre, aspects nationaux et exemples régionaux. Espace, populations, sociétés 4 (2):157-168.

Burnside R (2012) Demographic Change (Financial Scrutiny Unit Briefing 12/57). Scottish Parliament Information Centre (SPICe), Edinburgh.

Carstensen LL (2006) The influence of a sense of time on human development. Science 312 (5782):1913-1915.

Carstensen LL, Isaacowitz DM, Charles ST (1999) Taking time seriously: A theory of socioemotional selectivity. American Psychologist 54 (3):165.

Clark R, Ogawa N, Mason A (2007) Economic and policy implications of population aging. In: Clark R, Ogawa N, Mason A (eds) Population aging, intergenerational transfers and the macroeconomy. Edward Elgar Publishing Limited, Cheltenham, UK, pp 3-14

Coale AJ, Hoover EM (1958) Population growth and economic development in low-income countries. Princeton University Press, Princeton

Cocco JF, Gomes FJ (2012) Longevity risk, retirement savings, and financial innovation. Journal of Financial Economics 103 (3):507-529.

Crespo Cuaresma J, Lábaj M, Pružinský P (2014a) Prospective Ageing and Economic Growth in Europe. The Journal of the Economics of Ageing 3 (4):50-57.

Crespo Cuaresma J, Lutz W, Sanderson W (2014b) Is the demographic dividend an education dividend? Demography 51 (1):299-315.

Cutler DM, Poterba JM, Sheiner LM, Summers LH, Akerlof GA (1990) An aging society: opportunity or challenge? Brookings papers on economic activity:1-73.

Doyle Y, McKee M, Rechel B, Grundy E (2009) Meeting the challenge of population ageing. BMJ 339 (b3926).

European Commission (2010) Towards adequate, sustainable and safe European pension systems. Green Paper COM(2010)365 final. European Commission, Brussels.

Fries JF (1989) The Compression of Morbidity: Near or Far? The Milbank Quarterly 67 (2):208-232.

Fuchs VR (1984) "Though much is taken": Reflections on aging, health, and medical care. Milbank Memorial Fund Quarterly Health and Society 62 (2):142-166.

Fürnkranz-Prskawetz A, Ronald D, Lee S-HL, Lindh T, Mason A, Miller T, Mwabu G, Ogawa N, Soyibo A (2011) The economic consequences of population aging. NTA Bulletin No. 3.

Hamermesh DS (1985) Expectations, life expectancy, and economic behavior. The Quarterly Journal of Economics 100 (2):389-408. 
Hersch L (1944) De la démographie actuelle à la démographie potentielle. In: Melange des Études Economiques Offertes à William Rappard. Georg, Geneva,

Kemnitz A, Wigger BU (2000) Growth and social security: the role of human capital. European Journal of Political Economy 16 (4):673-683.

Lafortune G, Balestat G (2007) Trends in Severe Disability Among Elderly People: Assessing the Evidence in 12 OECD Countries and the Future Implications. OECD Health Working Papers 26. OECD Publishing. doi:10.1787/217072070078.

Lee R, Mason A (2010) Some macroeconomic aspects of global population aging. Demography 47 (1):S151-S172.

Lutz W (2009) The demography of future global population aging: Indicators, uncertainty, and educational composition. Population and Development Review 35 (2):357-365.

Lutz W, Crespo Cuaresma J, Sanderson W (2008a) The demography of educational attainment and economic growth. Science 319 (5866):1047-1048.

Lutz W, Goujon A, Wils A (2008b) The population dynamics of human capital accumulation. Population and Development Review 34 (Supp):149-187.

Lutz W, Sanderson W, Scherbov S (2008c) The coming acceleration of global population ageing. Nature 451 (7179):716-719.

Lutz W, Sanderson W, Scherbov S (2008d) Global and Regional Population Ageing: How Certain Are We of its Dimensions? Journal of Population Ageing 1 (1):75-97.

Manton KG, Gu X, Lamb VL (2006) Long-Term Trends in Life Expectancy and Active Life Expectancy in the United States. Population and Development Review 32 (1):81-105.

Mason A (2005) Demographic transition and demographic dividends in developed and developing countries. United Nations expert group meeting on social and economic implications of changing population age structures. United Nations, New York, pp 81-102.

Mason A, Lee R (2006) Reform and support systems for the elderly in developing countries: capturing the second demographic dividend. Genus:11-35.

Mason A, Lee R (2007) Transfers, capital, and consumption over the demographic transition. In: Clark R, Ogawa N, Mason A (eds) Population aging, intergenerational transfers and the macroeconomy. Edward Elgar Publishing Limited, Cheltenham, UK, pp 128-162

Mason A, Lee R (2011) Population aging and the generational economy: key findings. In: Lee R, Mason A (eds) Population Aging and the Generational Economy: Global Perspectives. Edward Elgar Publishing Limited, Cheltenham, UK, pp 3-31

Miller T (2001) Increasing longevity and Medicare expenditures. Demography 38 (2):215226.

Muszyńska MM, Rau R (2012) The Old-Age Healthy Dependency Ratio in Europe. Journal of population ageing 5 (3):151-162.

Panush N, Peritz E (1996) Potential demography: A second look. European Journal of Population 12 (1):27-39.

Patxot C, Rentería E, Sánchez-Romero M, Souto G (2011) Integrated results for GA and NTA for Spain: some implications for the sustainability of welfare state. Moneda y Crédito 231:7-51.

Philipov D, Goujon A, Di Giulio P (2014) Ageing dynamics of a human-capital-specific population. Demographic Research 31 (44):1311-1336.

Polder JJ, Bonneux L, Meerding WJ, Van Der Maas PJ (2002) Age-specific increases in health care costs. The European Journal of Public Health 12 (1):57-62.

Post T, Hanewald K (2012) Longevity risk, subjective survival expectations, and individual saving behavior. Journal of Economic Behavior \& Organization 86:200-220.

Prskawetz A, Sambt J (2014) Economic support ratios and the demographic dividend in Europe. Demographic Research 30 (34):963-1010. 
Riffe TLM, Spijker J, MacInnes J (2014) Decomposing and Recomposing the Population Pyramid by Remaining Years of Life. Presented at the Population Association of America Annual Meeting, Boston, USA, 1-3 May.

Rofman R, Oliveri ML (2012) Pension coverage in Latin America: Trends and determinants. Social Protection Discussion Papers 1217. World Bank.

Ryder NB (1975) Notes on Stationary Populations. Population Index 41 (1):3-28.

Sanderson WC, Scherbov S (2005) Average remaining lifetimes can increase as human populations age. Nature 435 (7043):811-813.

Sanderson WC, Scherbov S (2007a) A Near Electoral Majority of Pensioners: Prospects and Policies. Population and Development Review 33 (3):543-554.

Sanderson WC, Scherbov S (2007b) A new perspective on population aging. Demographic Research 16 (2):27-58.

Sanderson WC, Scherbov S (2008) Rethinking Age and Aging. Population Bulletin 63 (4).

Sanderson WC, Scherbov S (2010) Remeasuring Aging. Science 329 (5997):1287-1288.

Sanderson WC, Scherbov S (2013) The characteristics approach to the measurement of population aging. Population and Development Review 39 (4):673-685.

Scherbov S, Sanderson WC, Mamolo M (2014) Quantifying policy tradeoffs to support aging populations. Demographic Research 30 (20):579-608.

Seshamani M, Gray AM (2004) A longitudinal study of the effects of age and time to death on hospital costs. Journal of Health Economics 23 (2):217-235.

Siegel JS, Davidson M (1984) Demographic and Socioeconomic Aspects of Aging in the United States. Current population reports.

Spijker J, MacInnes J (2013a) Population ageing in Scotland: Time for a re-think? Scottish Affairs 85:53-74.

Spijker J, MacInnes J (2013b) Population ageing: the timebomb that isn't? British Medical Journal 347:f6598.

Spijker J, Riffe TLM, MacInnes J (2014) Incorporating time-to-death (TTD) in health-based population ageing measurements. Presented at the New Measures of Age and Ageing, Vienna, 3-5 December.

Striessnig E, Lutz W (2014) How does education change the relationship between fertility and age-dependency under environmental constraints? A long-term simulation exercise. Demographic Research 30:465-492.

Sullivan DF (1971) A single index of mortality and morbidity. HSMHA health reports 86 (4):347.

The Conference Board (2011) The Conference Board Total Economy Database, September $2011 \mathrm{http}: / /$ www.conference-board.org/data/economydatabase/.

The Select Committee on Public Service and Demographic Change (2013) Report of Session 2012-13: Ready for Ageing? HL Paper 140. The Stationery Office Limited, London.

Tyers R, Shi Q (2007) Demographic change and policy responses: Implications for the global economy. The World Economy 30 (4):537-566.

UN (2013a) National Transfer Accounts Manual: Measuring and Analysing the Generational Economy United Nations Department of Economic and Social Affairs. http://esa.un.org/wpp.

UN (2013b) World Population Prospects: The 2012 Revision. United Nations Department of Economic and Social Affairs. http://esa.un.org/wpp.

Van Solinge H, Henkens K (2010) Living longer, working longer? The impact of subjective life expectancy on retirement intentions and behaviour. The European Journal of Public Health 20 (1):47-51.

Vaupel JW, Loichinger E (2006) Redistributing Work in Aging Europe. Science 312 (5782):1911-1913. 
Wolf DA, Amirkhanyan AA (2010) Demographic Change and Its Public Sector Consequences. Public Administration Review 70:s12-s23.

Wong A, van Baal PHM, Boshuizen HC, Polder JJ (2011) Exploring the influence of proximity to death on disease-specific hospital expenditures: a carpaccio of red herrings. Health Economics 20 (4):379-400.

Wu L (2013) Inequality of Pension Arrangements Among Different Segments of the Labor Force in China. Journal of Aging \& Social Policy 25 (2):181-196.

Zweifel P, Felder S, Meiers M (1999) Ageing of population and health care expenditure: a red herring? Health Economics 8 (6):485-496. 


\section{VIENNA INSTITUTE OF DEMOGRAPHY}

\section{Working Papers}

Kuhn, Michael and Klaus Prettner, Population Structure and Consumption Growth: Evidence from National Transfer Accounts, VID Working Paper 3/2015.

Sobotka, Tomáš, Low Fertility in Austria and the Czech Republic: Gradual Policy Adjustments, VID Working Paper 2/2015.

Buber-Ennser, Isabella, Aspects of Gender Mainstreaming of Family and Work in Austria, VID Working Paper 1/2015.

Buber-Ennser, Isabella and Ralina Panova, Attitudes towards Parental Employment across Europe, in Australia and in Japan, VID Working Paper 5/201.

Kumar, Abhishek, Valeria Bordone and Raya Muttarak, Influence of Older Generation's Fertility Behaviours on Daughter's Desired Family Size in Bihar, India, VID Working Paper 4/2014.

Sobotka, Tomáš and Éva Beaujouan, Two is Best? The Persistence of a Two-child Family Ideal in Europe, VID Working Paper 3/2014.

Sander, Nikola, Guy J. Abel, Ramon Bauer and Johannes Schmidt, Visualising Migration Flow Data with Circular Plots, VID Working Paper 2/2014.

Barakat, Bilal, Revisiting the History of Fertility Concentration and its Measurement, VID Working Paper 1/2014.

Buber-Ennser, Isabella, Attrition in the Austrian Generations and Gender Survey, VID Working Paper 10/2013.

De Rose, Alessandra and Maria Rita Testa, Climate Change and Reproductive Intentions in Europe, VID Working Paper 09/2013.

Di Giulio, Paola, Thomas Fent, Dimiter Philipov, Jana Vobecká and Maria WinklerDworak, State of the Art: A Family-Related Foresight Approach, VID Working Paper 08/2013.

Sander, Nikola, Guy J. Abel and Fernando Riosmena, The Future of International Migration: Developing Expert-Based Assumptions for Global Population Projections, VID Working Paper 07/2013.

Caselli, Graziella, Sven Drefahl, Marc Luy and Christian Wegner-Siegmundt, Future Mortality in Low-Mortality Countries, VID Working Paper 06/2013.

The Vienna Institute of Demography Working Paper Series receives only limited review. Views or opinions expressed herein are entirely those of the authors. 